Department of Economics- FEA/USP

\title{
The impact of climate change on internal migration in Brazil
}

JAQUELINE OLIVEIRA

Paula Carvalho Pereda

WORKING PAPER SERIES № 2019-20 


\title{
DEPARTMENT OF ECONOMICS, FEA-USP \\ WORKING PAPER № 2019-20
}

\section{The impact of climate change on internal migration in Brazil}

\author{
Jaqueline Oliveira (oliveiraj@rhodes.edu)
}

Paula Carvalho Pereda (pereda@usp.br)

\begin{abstract}
:
Business-as-usual climate-change forecasts point to sharp temperature rises and agriculture yield losses in Brazil. We study the impact of these changes on internal migra-tion and population distribution. We employ a spatial equilibrium model in which the climate shapes workers' locational choices through the usual amenity-value channel and the novel indirect channel via agriculture wages. Our simulations reveal that migration rates are $5.9 \%$ higher, and that half million more people migrate inter-regionally under future climate conditions. Furthermore, climate change will likely exacerbate the country's regional inequalities, as the most developed regions gain population and welfare while the least developed regions lose.
\end{abstract}

Keywords: Climate change; Agriculture productivity; Internal migration; Regional inequality; Spatial equilibrium

JEL Codes: 015; Q54; R13; Q51 


\title{
The Impact of Climate Change on Internal Migration in Brazil
}

\author{
July 3, 2019
}

\begin{abstract}
Business-as-usual climate-change forecasts point to sharp temperature rises and agriculture yield losses in Brazil. We study the impact of these changes on internal migration and population distribution. We employ a spatial equilibrium model in which the climate shapes workers' locational choices through the usual amenity-value channel and the novel indirect channel via agriculture wages. Our simulations reveal that migration rates are $5.9 \%$ higher, and that half million more people migrate interregionally under future climate conditions. Furthermore, climate change will likely exacerbate the country's regional inequalities, as the most developed regions gain population and welfare while the least developed regions lose.
\end{abstract}

JEL Codes : O15, Q54, R13, Q51

Keywords: Climate Change, Agriculture Productivity, Internal Migration, Regional Inequality, Spatial Equilibrium 


\section{Introduction}

The influence of climate on people's lives is undeniable. Because we expect considerable changes in climate and temperature increases that differ across space, it is reasonable to conjecture that these changes will spur migration and reshape the spatial distribution of people and economic activity. Our goal in this paper is to quantify these phenomena.

Specifically, we turn to the case of Brazil to conduct our study. The country's continental dimensions and climate diversity imply that its regions will experience different temperature rises, a point illustrated in Figure $1 .^{1}$ Also, the Brazilian population censuses provide detailed data on migration flows at a fine geographic level. Brazil, therefore, offers an ideal setting to study the impact of climate change on internal migration patterns. ${ }^{2}$ Moreover, because a large share of the country's labor force is employed in agriculture, we examine the impact of climate change on migration through its effect on agricultural income. $^{3}$

For our quantitative exercise we propose a spatial equilibrium framework in which discrete-choice techniques are used to model workers' locational choices (Timmins (2007), Morten and Oliveira (2016)). The utility from living in a given location is a function of local attributes - wages, rental prices, climate, and non-climate amenities-and an idiosyncratic taste parameter. ${ }^{4}$ Importantly, our model departs from Timmins (2007) and distinguishes two channels through which climate may impact locational choice: the usual amenity-value channel and the novel indirect channel via agriculture wages. ${ }^{5}$ The distinction is possible because our workers choose location and employment sector-either in agriculture or in non-agriculture. We postulate that agriculture productivity-and therefore agriculture wages—is a function of climate. ${ }^{6}$ We also assume that each migrant

\footnotetext{
${ }^{1}$ According to the predictions generated by the Hadley CM3 global circulation model for a highemissions scenario, summer temperatures increase nearly 3 degrees Celsius on average and the interquartile range of these temperature changes is 3.6 degrees. We give more details on the predictions in Section 3.

${ }^{2}$ Other large developing countries like India and China do not possess detailed migration data from the population census. These countries also have unique barriers to internal migration that Brazil do not have, such as language and cultural diversity and, in the Chinese case, the hukou system that curtails rural to urban migration.

${ }^{3}$ Population census data reveal that about $23 \%$ of the country's labor force was employed in agriculture in 2010; in some locations this share was as high as 50\%. See Appendix Figure 1.

${ }^{4}$ Discrete-choice models inspired by McFadden (1973) have been recently used to compute the value of local amenities. See Timmins (2007) for temperature and rainfall, Bayer et al. (2009) for clean air, Klaiber and Phaneuf (2010) for open space, Sinha et al. (2018) for temperature, and Diamond (2016) for endogenous amenities that depend on city skill mix.

${ }^{5}$ Agronomic models predict a large degree of spatial variation in changes in potential crop yields as a result of climate change. More details in Section 3.

${ }^{6}$ Because the relationship between climate and agriculture yields is complex, we choose not to param-
} 
worker pays a relocation cost which depends on the distance between origin and destination. ${ }^{7}$ Workers' locational choice determines the demand for housing and the supply of labor at each location; local housing prices and wages in each sector are set by supplyand-demand. As workers migrate in response to the new climate conditions, wages and rents adjust which, in turn, further alter locational choices. Our analysis, therefore, accounts for general equilibrium effects of population re-sorting.

We estimate the parameters of the spatial equilibrium model using a two-step estimation procedure (Berry et al. (2004); Timmins (2007)). In the first step we employ rich bilateral migration flow data drawn from the 1980 to 2010 decennial population censuses to estimate the location-sector specific component of workers' indirect utility and the migration cost parameters. We assume that migration costs have a fixed component, capturing a general dislike of moving, and another component which depends on two factors: the geographic distance and the difference in temperatures between the worker's origin and a potential destination. Consistent with previous studies, the first-step estimates reveal that migration costs are significant. We also find that workers choose their locations based on differences in temperature between origin and possible destinations.

In the second step, we use the indirect utilities estimated in the first step, along with data on wages, rents, and climate (temperature, rainfall, and sunshine hours), to estimate the marginal utilities of income and climate amenities and the parameters in the equations that characterize the equilibrium in the labor and housing markets. We instrument changes in wages and labor force with measures of local labor demand shocks (Bartik (1991)) and labor market access derived from the model (Morten and Oliveira (2016)). Our estimates of the marginal utility of climate amenities indicate that Brazilians place a higher value on warmer winters than they place on cooler summers-a $31 \%$ difference.

We use our estimates to answer questions regarding the impact of warmer temperatures on (i) internal migration and, consequently, the spatial distribution of the workforce; (ii) the share of employment in agriculture; (iii) and the regional distribution of welfare. To carry out the simulations, we use information on future agriculture productivity from

eterize it. Instead, we rely on grid-level data from the Global Agro-Ecological Zones (GAEZ) to obtain estimates of potential crop yields under current and future climate.

${ }^{7}$ Bayer et al. (2009) have shown that the presence of migration costs biases the estimates of the preferences for amenities when these costs are not accounted for. Timmins (2007) have shown that costly adaptation to climate change is relevant when evaluating the welfare effects of climate change. Cropper and Sinha (2013) also find relevant moving costs for the US. These studies model migration costs as depending on the distance between the migrant's state of birth and the new location. Morten and Oliveira (2016) show that migration costs that depend on the travel time between origin and destination are important determinants of workers' choice of location in Brazil. We follow their approach when modeling migration costs. 
the Global Agro-Ecological Zones dataset (GAEZ) and temperature forecasts produced by the National Institute for Space Research (INPE). ${ }^{8}$ The agriculture data are available under current and future climate conditions so we can use the predicted change in yields to estimate how climate change will affect agriculture wages.

We feed data on average temperatures and attainable agriculture yields into our spatial equilibrium model to simulate the bilateral migration probabilities-and sector choiceand, in turn, the population distribution under future climate scenarios. We then calculate the changes in internal migration flows and regional welfare relative to those prevailing under the current climate. We carry out this exercise under three experiments: (i) considering that climate impacts only the amenity value of locations, (ii) assuming that climate only affects agriculture productivity, and (iii) assessing both channels. We run the simulations under two scenarios: a high-emissions scenario and a low-emissions scenario.

Under the third experiment, the high-emissions scenario yields an aggregate migration rate $5.79 \%$ higher than the migration rate under the current climate. Under the first experiment the increase in migration rate is $50 \%$ smaller, which highlights the need to account for changes in the agriculture sector wages. The share of employment in agriculture is also affected by climate change: it is $20 \%$ lower under future climate, an effect spurred mainly by the losses in agriculture yields.

Turning to the internal migration flow pattern among Brazil's macro-regions, and still considering the high-emissions scenario, we find that nearly half a million more people migrate inter-regionally. Furthermore, climate change will likely deepen regional inequalities. The Northeast-the poorest region-is the biggest loser. The region loses about $1.5 \%$ of its population to other regions, mostly due to an increase in out-migration to the Southeast; there, expected utility falls. The North and South also lose population and welfare but in smaller magnitudes. The Southeast—-the richest and most industrialized regionand the Midwest - the country's new agriculture frontier-are the winners. These regions gain $1.4 \%$ and $1.2 \%$ of their population, respectively; the gain is attributed mostly to an increase in in-migration. They also experience increases in expected utility. These gains might be explained by the fact that several locations that comprise these two regions experience gains in agriculture yields under the new climate, and that winter temperatures rise more than summer temperatures. ${ }^{9}$

\footnotetext{
${ }^{8}$ Crop potential yields from the GAEZ dataset are generated using agronomic models and highresolution data on climatic and soil conditions. The estimates are available for 255,680 grids covering the Brazilian territory (around 8.5 million square $\mathrm{km}$ ) regardless of whether the place produces the crop. More details in Section 3.

${ }^{9}$ Previous research finds that climate change leads to regional differences in welfare (Cropper and Sinha
} 
The role of migration as a strategy to cope with climate change has been examined in Findley (1994), Barrios et al. (2006), Saldaña-Zorrilla and Sandberg (2009), Drabo and Mbaye (2011), Marchiori and Schumacher (2011), and Marchiori et al. (2012). Most of these studies, however, focus on partial equilibrium modeling. Our analysis, on the other hand, highlights the importance of general equilibrium effects: ignoring these leads to overestimation of the overall impact of climate change on internal migration. ${ }^{10}$ Additionally, a large fraction of the literature focus on extreme events such as earthquakes, tornadoes, hurricanes, floods, and droughts, as opposed to long-term climate change, and do not consider permanent, or lifetime, migration. ${ }^{11}$ As noted by Baez et al. (2017), people affected by natural disasters normally receive social assistance, usually not available to people affected by long-term changes in climate.

Our paper also relates to another three strands of literature. First, a literature concerned with the estimation of spatial equilibrium models to understand the connection between population sorting and a wide variety of economic phenomena. ${ }^{12}$ Second, the literature measuring the willingness to pay for climate amenities in developed (Blomquist et al. (1988), Cragg and Kahn (1997), Maddison and Bigano (2003), Rehdanz and Maddison (2009), Cropper and Sinha (2013), and Albouy et al. (2016)) and developing countries (Maddison (2003), Mueller (2005), and Timmins (2007)). Finally, the literature that studies the adaptation strategies to climate change. ${ }^{13}$

This paper is organized as follows. The next section lays out the spatial equilibrium

(2013)) and international migration (Marchiori and Schumacher (2011)); the disparities are mainly driven by low income regions being more vulnerable to climate change and low income individuals having capital constraints to pay for moving costs (Baez et al. (2017); Drabo and Mbaye (2011)).

${ }^{10}$ Partridge et al. (2017) criticize the lack of theoretical models to evaluate the relationship between climate and migration and advocate in favor of spatial equilibrium models to assess such impacts.

${ }^{11}$ Baez et al. (2017) studies the effect of heat exposure on migration in Central America countries. SaldañaZorrilla and Sandberg (2009) finds evidence that climate-related disasters affect migration in Mexican municipalities. Gray and Mueller (2012) and Martin et al. (2014) analyze flooding effects in Bangladesh. Findley (1994) examines the relationship between droughts and migration in Mali. Marchiori et al. (2012) assesses the impact of weather anomalies on migration in Africa. Hornbeck (2012) finds evidence of large population declines from the American Dust Bowl in the 1930s.

${ }^{12}$ See Bayer et al. (2007) for a framework to estimate preferences for schools in U.S. neighborhoods; Albouy (2009) for a study of the effects of taxation on employment and wages; Diamond (2016) for a model of endogenous production of amenities that explains the college gap in the U.S.; Morten and Oliveira (2016) for the welfare effects of increased labor market connectivity through road networks; Mangum (2015) for a dynamic spatial equilibrium model with barriers to labor adjustment to local labor demand shocks.

${ }^{13}$ See Seo and Mendelsohn (2008) and Seo et al. (2010) for how farmers in Africa adjust their choices of livestock species in face of changes in climate; Hornbeck (2012) for a study of the economic adjustments in the early 20th century America to a large environmental shock; Taraz (2017) for a study of Indian farmers' coping strategies using irrigation investments and crop adaptation; da Cunha et al. (2014) for the role of irrigation in allowing Brazilian farms to avoid some of the adverse effects of climate change. 
model we employ in our quantitative analysis. Section 3 describes the datasets we utilize to measure economic variables, as well as the building of historical climate data. Section 4 outlines the estimation strategy and presents the estimates of structural parameters. Section 5 presents our simulations of the effects of climate change on migration and welfare. Section 6 concludes.

\section{The Model}

Our analysis begins with the setup of a spatial equilibrium model. The model features workers choosing the location in which to live and the sector of employment after comparing the wages, housing prices, and the amenities that locations provide to their residents. The workers' choice is also guided by idiosyncratic tastes for location and sectorassumed i.i.d across workers, location, and sector-and by a bilateral migration cost parameter. The climate plays a role in this decision through two channels: (i) the amenity value of locations and (ii) the wages enjoyed by workers who choose the agriculture sector. Next, we lay out the details of the model.

\subsection{The locational choice}

Consider a country with $J$ locations, and let $j$ index the origin and $k$ the destination. Each location offers employment in two sectors, agriculture and non-agriculture, indexed by $s=a, m$. At time $t$, individuals living in location $k$ and working in sector $s$ consume a bundle of nationally produced agriculture and non-agriculture goods, $B_{k s t}$, and locally produced housing, $H_{k s t}$; they cost $p_{t}$ and $r_{k t}$, respectively. ${ }^{14}$ They also enjoy location amenities, climate, $C_{k t}$, and non-climate, $A_{k t}$, and sector-of-employment amenities, $S_{s t}$. Preferences over consumption goods and housing are the Cobb-Douglas type, which yield the

\footnotetext{
${ }^{14}$ Assuming that agriculture goods are produced nationally implies that their prices do not vary across locations. Thus, any effect that climate change has on prices does not affect locational choice. One obvious concern is that trade costs are substantial enough to invalidate this assumption so that food prices are higher in locations that face higher trade costs. We argue that for the time horizon over which we perform the climate-change simulations it is likely that local markets will be well integrated so that these costs would be of second-order importance.
} 
following $(\log )$ indirect utility function ${ }^{15}$

$$
v_{k s t}=v_{t}+\log w_{k s t}-\lambda_{r} \log r_{k t}+\lambda_{c} C_{k t}+\lambda_{A} A_{k t}+\lambda_{s} S_{s t .}{ }^{16}
$$

An individual who starts in location $j$ and moves to $k$ in period $t$ pays a migration cost, $\mu_{j k}$, which depends on the following components

$$
\mu_{j k}=\mu_{f} \mathbb{1}\{j \neq k\}+\mu_{d} D_{j k}+\mu_{c} C_{j k}
$$

where $\mathbb{1}\{j \neq k\}$ indicates if the destination is different from the origin, and captures a fixed utility cost of migrating; $D_{j k}$ is a vector of pairwise distance bins, and captures a component associated with the travel time; $C_{j k}$ is a vector that measures the "climate distance" between $j$ and $k$, and reflects the like or dislike to live somewhere where the climate is different from that of the current location.

Finally, before choosing a location and a sector, an individual draws a $J \times 2$ vector of i.i.d. idiosyncratic taste shocks. Assuming taste shocks are $\epsilon_{n k s t} \sim$ Type I Extreme Value, with variance $\sigma^{2}$, the utility that individual $n$ who starts in location $j$ derives from living in location $k$ and working in sector $s$ in period $t$ is

$$
v_{n j k s t}=\frac{v_{t}}{\sigma}+\frac{1}{\sigma} \log w_{k s t}-\frac{\lambda_{r}}{\sigma} \log r_{k t}+\frac{\lambda_{c}}{\sigma} C_{k t}+\frac{\lambda_{A}}{\sigma} A_{k t}+\frac{\lambda_{s}}{\sigma} S_{s t}-\frac{\mu_{j k}}{\sigma}+\epsilon_{n k s t}
$$

and the likelihood that an agent migrates from $j$ to $k$ to work in sector $s$ in period $t$ is

$$
\begin{aligned}
\pi_{j k s t} & =\operatorname{Pr}\left(v_{n j k s t} \geq v_{n j l q t} \forall l \neq k, \forall q \neq s\right) \\
& =\frac{\exp \left(\frac{v_{k s t}}{\sigma}-\frac{\mu_{j k}}{\sigma}\right)}{\sum_{q \in\{a, m\}} \sum_{l=1}^{J} \exp \left(\frac{v_{l q t}}{\sigma}-\frac{\mu_{j l}}{\sigma}\right)} .
\end{aligned}
$$

\footnotetext{
${ }^{15}$ Individuals solve

$$
\begin{array}{ll}
\max _{B_{k s t}, H_{k s t}} & \left(B_{k s t}\right)^{1-\lambda_{r}}\left(H_{k s t}\right)^{\lambda_{r}} \exp \left(\lambda_{c} C_{k t}\right) \exp \left(\lambda_{A} A_{k t}\right) \exp \left(\lambda_{s} S_{k t}\right) \\
\text { s.t. } & p_{t} B_{k s t}+r_{k t} H_{k s t} \leq w_{k s t},
\end{array}
$$

which results in the indirect utility function

$$
\begin{gathered}
V_{k s t}=\left(\left(1-\lambda_{r}\right) \frac{w_{k s t}}{p_{t}}\right)^{1-\lambda_{r}}\left(\lambda_{r} \frac{w_{k s t}}{r_{k t}}\right)^{\lambda_{r}} \exp \left(\lambda_{c} C_{k t}\right) \exp \left(\lambda_{A} A_{k t}\right) \exp \left(\lambda_{s} S_{k t}\right) . \\
{ }^{16} \text { where } v_{t}=\lambda_{r} \log \lambda_{r}+\left(1-\lambda_{r}\right) \log \left(1-\lambda_{r}\right)-\left(1-\lambda_{r}\right) \log p_{t} .
\end{gathered}
$$
}


Given the initial distribution of the population, $N_{j}^{0}$, the supply of labor at location $k$ and sector $s$ in period $t$ is

$$
L_{k s t}=\sum_{j=1}^{J} N_{j}^{0} \pi_{j k s t} .
$$

From our data we observe the share of people who migrated between origin-destination pairs of locations by sector of employment $\left(\pi_{j k s t}\right)$ and the bilateral migration cost components $\left(\mathbb{1}\{j \neq k\}, D_{j k}\right.$, and $\left.C_{j k}\right)$. We estimate the destination-sector-specific component of the indirect utility $\left(\frac{v_{k s t}}{\sigma}\right)$ and the cost function parameters, divided by the standard deviation of the idiosyncratic taste shock $\left(\frac{\mu_{f}}{\sigma}, \frac{\mu_{d}}{\sigma}\right.$, and $\left.\frac{\mu_{c}}{\sigma}\right)$.

\subsection{The determination of prices}

The supply of labor at local labor markets is determined by the individuals' locational choice. We now propose a simple characterization of the labor demand. We assume that in each period the many homogenous firms in location $k$, sector $s$ produce a final tradable good using only labor as input. Production takes place according to the function $Y_{k s t}=T_{k s t} L_{k s t}^{\alpha_{s}}$, where $L_{k s t}$ is labor, $T_{k s t}$ is productivity, and $\alpha_{s}$ measures the returns to labor inputs in each sector. ${ }^{17}$ We further assume that

$$
T_{k s t}=T_{k t} \exp \left(g_{s}\left(C_{k t}\right)+v_{k s t}\right)
$$

where $T_{k t}$ captures the location-wide determinants of productivity, and $g_{s}\left(C_{k t}\right)$ maps the impact of the climate; $v_{k s t}$ picks up other location- and sector- specific shocks. The assumption that labor markets are competitive yields

$$
\log w_{k s t}=c+\log T_{k t}+g_{s}\left(C_{k t}\right)+\gamma_{s} \log L_{k s t}+v_{k s t}
$$

where $c=\log \left(\alpha_{s}\right)$, and $\gamma_{s}=-\left(1-\alpha_{s}\right)$. In Equation 4, we assume that climate only has a direct impact on productivity in the agriculture sector so that $g_{m}()=$.0 . We do not parameterize the function $g_{a}($.$) but instead rely on agronomic models to predict the effect$ of climate on agriculture yields. ${ }^{18}$

\footnotetext{
${ }^{17}$ We assume that land is a fixed factor of production and, as such, its omission does not interfere with the estimates of our main parameters because we take the first difference of the variables. Besides, for the simulations we employ potential agriculture yield data from agronomic models which account for a variety of soil conditions.

${ }^{18}$ See a detailed discussion in Section 3.3.
} 
The equilibrium in the housing market determines the price of housing units. Following Diamond (2016), each location has a well-developed housing market. Developers produce housing units using construction materials and land. Assuming developers are price takers and housing units are homogeneous, the price of housing units is set equal to the marginal cost. In the asset market equilibrium, prices are set equal to the discounted value of rents, yielding $r_{k t}=i_{t} M C_{k t}$, where $i_{t}$ is the interest rate. We assume further that housing is owned by absentee landlords who rent the houses to local residents. Developers' marginal costs depend on the cost of land; the cost of land, in turn, is a function of the aggregate housing demand. Thus, the equation that characterizes the equilibrium in the housing market is

$$
\log r_{k t}=\log i_{t}+\eta \log \left(\sum_{s \in\{a, m\}} w_{k s t} L_{k s t}\right)+\zeta_{k t}
$$

where $\eta$ is the housing supply elasticity, and $\zeta_{k t}$ is the idiosyncratic component of housing prices. In Equation 5, we observe local rental prices $\left(r_{k t}\right)$, wages $\left(w_{k s t}\right)$ and labor $\left(L_{k s t}\right)$ by sector. We estimate the housing supply elasticity parameter $(\eta)$.

\subsection{The climate and the spatial equilibrium}

Given the initial distribution of the population, $N_{j}^{0}$, the spatial equilibrium is defined by bilateral migration probabilities $\left(\pi_{j k s t}^{*}\right)$, wages $\left(w_{k s t}^{*}\right)$, and rents $\left(r_{k t}^{*}\right)$ that satisfy Equations 3,4 , and 5. In equilibrium, the marginal mover is indifferent between staying in their current location or moving; also, the labor and housing markets clear. A change in climate that impacts locations differently and, in turn, alters relative location amenity values and agriculture wages, induces more people to move and reshapes the spatial and sectoral distribution of the labor force. As people re-locate, local wages and housing prices adjust, further impacting locational choice. A new equilibrium is reached when no one has an incentive to migrate.

\section{Data}

\subsection{Wages and rents}

To calculate wages, rents, labor, and migration flows and estimate the key parameters in Equations 1, 4, and 5, we use micro data from decennial population censuses spanning the 
1980-2010 period. The finest level of geography is the municipality. The municipalities are grouped into meso-regions. ${ }^{19}$

Workers aged 25 to 75 constitute the sample we use to calculate regional averages. The wage is the monthly labor income divided by total monthly hours of work, both in the main occupation; the rental price is the monthly amount paid in rents divided by the number of rooms. We convert nominal wages and rents to 2010 BRL (Brazilian Reais), and then use the average exchange rate in 2010 to convert them to 2010 US\$. ${ }^{20}$

A feature of Brazil's population census that is crucial to our study is the availability of data on each worker's municipality of residence five years prior to the census year. This feature enables us to employ five-year bilateral migration flow data to estimate migration costs and predict bilateral migration probabilities under future climate scenarios. Finally, data on workers' sector of employment allow us to model the choice between agriculture and non-agriculture jobs. ${ }^{21}$

\subsection{Weather and climate}

To estimate the marginal utility of climate amenities in Equation 1, we employ 10-year averages of the climate variables (mid-run climate); the averages are taken over the census year and nine years prior to the census, so that we end up with averages covering the 1971-1980, 1982-1991, 1991-2000, and 2001-2010 periods. $^{22}$ The mid-run climate data reflects the average exposure of workers to the climate in each meso-region. We use 10year averages instead of 30-year averages (long-run climate) because: (i) our estimation strategy relies on temporal variation in climate conditions; (ii) 10-year averages mitigate the influence of ENSO $\mathrm{cycles}^{23}$; and (iii) we want to explore the average exposure of individuals to climate before their potential moving (moving is observed from 1-5 years

\footnotetext{
${ }^{19}$ The Brazilian Bureau of Statistics (IBGE) groups municipalities into meso-regions, which are homogeneous areas with shared cultural history, natural resources, and connectivity. See http://ibge.gov.br/english/for details.

${ }^{20}$ The 2000 Census did not collect data on rentals. To fill this gap, we use rental prices data from the 1999 Brazilian Household Survey (PNAD). The survey is statistically representative for Brazil and, importantly, allows us to identify the households' municipality of residence. We calculate the weighted average rental prices for a meso-region using the households' survey sample weights.

${ }^{21}$ See Appendix Table 1 for summary statistics.

${ }^{22}$ Dell et al. (2012), for example, use 15-year mean climate to assess longer term effects of climate on GDP growth; Dell et al. (2014) recommend using decadal data instead of annual shocks when employing panel data techniques.

${ }^{23}$ The 10-year span mitigates the influence of El Niño-Southern Oscillation (ENSO) cycle on the averages. The ENSO cycle is a scientific term for fluctuations in air temperatures in the east-central Equatorial Pacific. It has two opposite phases: El Niño (higher temperatures) and La Niña (lower temperatures). El Niño and La Niña typically occur every two to seven years.
} 
prior the census years).

We calculate the mid-run averages from historical daily weather station data on temperatures, rainfall, and sunshine hours collected by the Brazilian Institute of Meteorology. ${ }^{24}$ We construct summer (Dec-Feb) and winter (Jun-Aug) averages for each mesoregion. ${ }^{25}$ Appendix Figures 2-7 show the spatial variation in the climate variables over time. Appendix Figures 8-13 present the temporal variation: the first difference of the mid-run climate data. From the Figures, we observe temporal variability within the mesoregions. For summer temperatures, the 1980's seemed to be much warmer than the previous and following decades. This behavior is less observed during winter and for the other variables considered (rainfall and sunshine).

To simulate the impact of changes in average temperatures on the spatial equilibrium we require data on current, or baseline, and future climate conditions. ${ }^{26}$ Our baseline climate corresponds to 30-year average summer and winter temperatures constructed from the daily weather station data spanning the 1961-1990 period. ${ }^{27}$ Data on future climate conditions are sourced from the National Institute for Space Research (INPE). The INPE calculates regional climate change over South America by downscaling Global Climate Models (GCM). Regional models are more suitable for studying local impacts of climate change. ${ }^{28}$

INPE predictions rely on scenarios generated by the IPCC's $5^{\text {th }}$ Assessment Report. We consider two scenarios: the pessimistic scenario, referred to as $\mathrm{A} 2$, and the optimistic scenario, B1. The A2 scenario describes a high population growth scenario (15 billion by 2100), slower technological change, and high carbon emissions; the B1 scenario assumes a low increase in population that peaks by 2050 and declines thereafter, the introduction of clean technologies, and carbon emissions equivalent to $65 \%$ of the total emissions in A2 scenario. ${ }^{29}$ Figure 1 displays the spatial distribution of temperature changes under

\footnotetext{
${ }^{24}$ Brazil has a network of weather stations with good coverage in the country's coast but low density in the interior, particularly the North and Midwest. The institute collects weather station data since January of 1961.

${ }^{25}$ We apply a kriging interpolation technique to calculate meso-region data (using the meso-region centroids) from weather station coordinates. See Appendix A.2 for a detailed discussion about the kriging technique.

${ }^{26}$ We do not assess changes in rainfall and sunshine hours for two reasons. First, data on future sunshine hours are not available. Second, the climate-change data on rainfall are volatile and very sensitive to the choice of GMCs and scenarios, so we decided not to incorporate those into our simulations.

${ }^{27}$ The maps with the spatial distribution of the 30-year averages are available upon request.

${ }^{28}$ See Appendix A.3 for details on the Regional Climate Models (RCMs) and GCMs.

${ }^{29}$ We overlay the gridded dataset on a map of meso-region polygons and calculate the average of the grid values, weighted by the grid area within the meso-region polygon.
} 
$\mathrm{A} 2$ and $\mathrm{B} 1$ scenarios relative to the baseline climate. The figure reveals that temperatures are expected to increase in most of the country, especially in the Midwest. We do see, however, that there is considerable spatial variation in how much summer and winter temperatures are predicted to rise.

\subsection{Agriculture yields}

To model the complex relationship between climate and agricultural productivity, represented by the function $g_{a}($.$) in Equation 4, we source grid-level data on agriculture yields$ from the Global Agro-ecological Zones (GAEZ) project, developed by the International Institute for Applied System Analysis (IIASA) and the UN's Food and Agriculture Organization (FAO). The GAEZ project draws on state-of-the-art agronomic models to calculate daily potential crop yields from high-resolution data on climatic and soil conditions under a set of assumptions about input use such as water, labor, and farm management. ${ }^{30}$

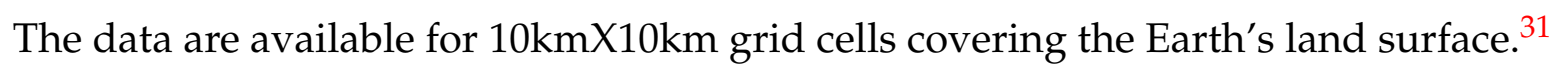

From the GAEZ project we obtain attainable crop yield data for the baseline climate (1961-1990) and future climate (2041-2070). Future climate predictions are available for several combinations of emission scenarios and GCMs. In our simulations, we adopt the predictions generated by the Hadley Centre Coupled Model version 3 (HadCM3) for scenarios $\mathrm{A} 2$ and $\mathrm{B} 1 .^{32}$

We harness data on potential yield for 11 crops for each of the 255,680 grids-nearly 3.3 million square miles-covering the Brazilian territory. The selected crops are soybean, maize, sugarcane, wheat, citrus fruits, cassava, banana, coffee, rice, beans, and tobacco, which constituted on average $96.7 \%$ of total agricultural production and $91.8 \%$ of total crop area in 2010 (Agriculture Surveys, PAM-IBGE). We average the grid-cell data to calculate meso-region crop yield in US\$ $/$ ha. ${ }^{33}$

\footnotetext{
${ }^{30}$ The attainable crop yield estimate we source from the GAEZ dataset is computed under the assumption of rain-fed water supply and an intermediate-level use of inputs. Intermediate-level input use means the farming system is partially market oriented, production relies on some mechanization and is moderately labor intensive. Rain-fed assessments assume the use of conventional tillage systems.

${ }^{31}$ Appendix A.4 details the geo-referenced inputs and features employed in crop yield predictions.

${ }^{32} \mathrm{HadCM} 3$ is a global model developed in 1999 and it draws on the IPCC's $3^{\text {rd }}$ and $4^{\text {th }}$ (AR4) Assessment Reports. (See Appendix A.4 for more information on alternative models and scenarios from GAEZ dataset.) It is worth mentioning that the temperature predictions we use to evaluate climate amenities described in the previous section draws on the $5^{\text {th }}$ Assessment Report (AR5) instead. The average temperature predictions from the AR5, however, are compatible with the crop yields prediction from the GAEZ.

${ }^{33}$ Here also we overlay the gridded dataset on a map of meso-region polygons. If a polygon overlaps multiple grids, we calculate the average of the grid values, weighted by the grid area within the mesoregion polygon. We use FAOSTAT average producer price per crop in US\$/ton to convert yields from
} 
We then aggregate the value of potential crop yield to create a single measure of mesoregion agriculture yields for the baseline climate and future climate under A2 and B1 scenarios according to

$$
\text { yields } k=\sum_{c=1}^{11} f_{c k} \text { yields } s_{c k}
$$

where $k$ is the meso-region, $c$ is the crop, and $f_{c k}$ the fraction of crop $c$ in total crop area. ${ }^{34}$

Figure 2 shows the spatial distribution of the agriculture yields changes for the A2 and B1 scenarios relative to the baseline climate. ${ }^{35}$ The most adversely affected areas are located in the North and Northeast; the few meso-regions potentially seeing an increase in agriculture productivity are located in the Midwest and the Southeast, and in specific regions on the "agriculture frontier" at the borders of the Amazon forest. ${ }^{36}$

\section{Estimation of structural parameters}

Section 2 laid out the key elements of the spatial equilibrium model: the workers' locational choice, the direct impact of the climate on agriculture wages, and the endogenous determination of real wages and rents. The current section presents the empirical strategy deployed to estimate the structural parameters governing these relationships.

\subsection{Migration costs}

First we estimate the parameters governing the costs of migrating between location pairs. Taking the log of Equation 2, and adding an error term to capture unobservable compo-

ton/ha to US\$/ha and deflate yields to 2010 prices using FAOSTAT's US\$ deflator.

${ }^{34}$ More specifically, $f_{c k}=\left(\sum_{t=1990}^{2010}\right.$ Area $\left._{c k t}\right) /\left(\sum_{i=1}^{11} \sum_{t=1990}^{2010}\right.$ Area $\left._{i k t}\right)$. Data on the crop area come from the Agricultural Survey (PAM-IBGE); they are available annually from 1990 to 2010. We hold $f_{c k}$ at current levels when calculating meso-region agriculture yields for future climate scenarios. However, one valid concern is that crop choice is likely altered by changes in climate. In this case, changes in crop choice could indeed lead us to understate the agriculture yields and, therefore, overstate the fall in the share of agriculture in employment under future climate conditions. We argue, however, that migration flows would be less affected to the extent that this issue likely impacts agriculture wages in all of the meso-region in the same fashion.

${ }^{35}$ The values depicted in the figure are percent changes, that is, $\left(y i e l d s_{k}^{s c o}-y i e l d s_{k}^{\text {bline }}\right) / y$ ields $s_{k}^{\text {bline }}$, where $s c o=\mathrm{A} 2, \mathrm{~B} 1$.

${ }^{36}$ Appendix Figure 14 shows the agriculture yield computed for baseline and future climates. Under the baseline climate, the Midwest, South, and Northeast house the most productive agriculture areas; their production capacity is attributed to their potential for maize, sugarcane, and soybeans. 
nents of migration costs, yields

$$
\log \pi_{j k s t}=\delta_{k s t}+\delta_{j t}-\frac{\mu_{f}}{\sigma} \mathbb{1}\{j \neq k\}-\frac{\mu_{d}}{\sigma} D_{j k}-\frac{\mu_{c}}{\sigma} C_{j k}+\frac{1}{\sigma} \xi_{j k s t},
$$

where $\delta_{k s t}=\frac{v_{k s t}}{\sigma}$ is a destination-sector-year fixed effect, and $\delta_{j t}$ is an origin-year fixed effect. ${ }^{37} D_{j k}$ are indicators for the distance between $j$ and $k$, measured in $100 \mathrm{~km}$, and $C_{j k}$ are indicators for the absolute difference in historical average temperatures between $j$ and $k^{38}$

We harness data on bilateral migration flows and choice of sector of employment to estimate $\frac{\mu_{f}}{\sigma}, \frac{\mu_{d}}{\sigma}$, and $\frac{\mu_{c}}{\sigma}$. To handle the large number of zero bilateral migration flows observed in the data (56.3\% of total flows), we employ a Poisson ML estimation strategy. Table 1 presents the estimates of the parameters $\frac{\mu_{f}}{\sigma}, \frac{\mu_{d}}{\sigma}$, and $\frac{\mu_{c}}{\sigma}$ in Equation 7. The results suggest that there are substantial migration costs. ${ }^{39}$ Migration entails a fixed utility cost, captured by the coefficient on the indicator $\mathbb{1}\{j \neq k\}$. These costs alone are important when assessing the welfare effects of climate change, as it relates to people's ability to adapt to changes in climate by moving to more preferred locations. Additionally, moving costs depend on geographic location. Workers are less likely to migrate to a destination that is further away from the origin. Finally, individuals dislike moving to a destination with historical temperature different from that of their origin.

To assess the model's goodness of fit, Figure 3 plots the predicted against the actual bilateral migration probabilities and agriculture share on meso-region employment. The plots show the model matches the data considerably well—the R-squared is 0.99 .

With the estimate of the cost parameters at hand, we move to the estimation of the remaining parameters of the indirect utility function governing workers' locational choice and the housing elasticity.

\footnotetext{
${ }^{37} \delta_{j t}=-\log \left(\sum_{q \in\{a, m\}} \sum_{l=1}^{J} \exp \left(\frac{v_{l q t}}{\sigma}-\frac{\mu_{j l}}{\sigma}\right)\right)$.

${ }^{38}$ We add five distance bins (in $100 \mathrm{~km}$ ): Distance $_{j k}[0.2,0.4)$, Distance $_{j k}[0.4,0.8)$, Distance $_{j k}[0.8,1.6)$, Distance $_{j k}[1.6,3.2)$, and Distance $j k[3.2, \max ) ;$ Distance $_{j k}[0,0.2)$ is the omitted category. The temperaturedifference bins are: $\left|T_{j}-T_{k}\right|\left[1^{o}, 2^{o}\right),\left|T_{j}-T_{k}\right|\left[2^{o}, 3^{o}\right),\left|T_{j}-T_{k}\right|\left[3^{o}, 4^{o}\right)$, and $\left|T_{j}-T_{k}\right|\left[4^{o}, \max \right) ; \mid T_{j}-$ $T_{k} \mid\left[0^{o}, 1^{o}\right)$ is the omitted category. We do not include bilateral travel times as a component of the bilateral migration cost, but we conclude that our results are robust to that addition. The results from this robustness check are available upon request.

${ }^{39}$ Other studies have modeled moving costs when estimating the value of climate (Timmins (2007), Cropper and Sinha (2013)) and air pollution (Bayer et al. (2009)). For a more comprehensive study of the role of transport costs on migration and welfare, see Morten and Oliveira (2016).
} 


\subsection{Elasticities}

The next step is to decompose the destination-location-year fixed effects of the indirect utility into its main components, and to estimate the parameters associated with climate amenities. Taking the first difference of Equation 1, and using the estimate of $\frac{v_{k s t}}{\sigma}$ from Equation $7, \hat{\delta}_{k s t}$, we have

$$
\Delta \widehat{\delta}_{k s t}=\frac{1}{\sigma}\left(\Delta \log w_{k s t}+\lambda_{r} \Delta \log r_{k t}+\lambda_{c} \Delta C_{k t}+\lambda_{A} \Delta A_{k t}+\lambda_{s} \Delta S_{s t}\right) .
$$

We use data from the 2009 Household Budget Survey (Pesquisa de Orçamentos Familiares) to estimate the share of housing on total income, $\hat{\lambda}_{r}=0.2$. We do not observe nonclimate and sector-of-employment amenities; we, therefore, assume that $\frac{\lambda_{A} \Delta A_{k t}}{\sigma}+\frac{\lambda_{s} \Delta S_{s t}}{\sigma}=$ $a_{\text {state }, t}+a_{\mathrm{s}}+\psi_{k s t}$, where $a_{\text {state, } t}$ is state-year fixed effects, $a_{\mathrm{s}}$ is an indicator for agriculture sector, and $\psi_{k s t}$ is an idiosyncratic amenity growth shock. The estimating equations, therefore, are

$$
\Delta \widehat{\delta}_{k s t}=a_{\text {state }, t}+a_{\mathrm{s}}+\frac{1}{\sigma}\left(\Delta \log w_{k s t}+0.2 \Delta \log r_{k t}+\lambda_{c} \Delta C_{k t}\right)+\psi_{k s t},
$$

and

$$
\Delta \log r_{k t}=r_{\text {state }, t}+\eta \Delta \log \left(\sum_{s \in\{a, m\}} w_{k s t} L_{k s t}\right)+\zeta_{k t},
$$

for the income elasticity of housing prices; $r_{\text {state }, t}$ captures state-specific temporal changes in the growth of living costs, and $\zeta_{k t}$ is an idiosyncratic error component.

We estimate the parameters from Equations 8 and 9 using a 3SLS estimator which allows for an arbitrary correlation structure between the error terms. The identification of the vector of parameters $\lambda_{c}$ relies on time variation in climate amenities instead of crosssectional variation. Our measures of climate amenities are 10-year averages of summer and winter temperatures (in ${ }^{\circ} \mathrm{C}$ ), 10-year averages of accumulated summer and winter rainfall (mm/month), and 10-year averages of sunshine hours (in hours/month); the averages are taken over the span of 10 years preceding the census. The approach enables us to control for any time-invariant unobservable location features correlated with temperature and rainfall.

One issue we might face in our empirical analysis is mean reversion. Mean reversion would occur, for example, if some regions of the country observed much warmer summers in a given period followed by a recovery to "normal" levels in the subsequent period. In this event, migration may temporarily respond to changes in short-run cli- 
matic conditions, with people migrating back to their origin locations once temperatures revert to their long-run levels, but permanent migration would see no impact. We argue that while this issue may be pervasive in studies that employ annual weather variation (Dell et al. (2012)), it is less likely to affect our estimates which rely on changes in 10-year averages.

The remaining challenge is the correlation between unobservable non-climate amenity growth and wage growth. Locations that experience faster productivity gains may also see a faster rise in both publicly- and privately-provided amenities. Additionally, labor supply at a given destination is a function of wages and housing prices, which leads to simultaneity bias. To address these issues, we use two instruments. The first is a local labor demand shifter, known as Bartik shocks (Bartik (1991)). They serve as instruments for wage growth in both agriculture and non-agriculture sectors. Bartik shocks are calculated as follows

$$
\Delta \text { Bartik }_{k t}=\sum_{i n d}\left(\log w_{i n d,-k, t}-\log w_{i n d,-k, t-10}\right) \frac{L_{i n d, k, t_{0}}}{L_{k, t_{0}}},
$$

where ind indexes the industry, $t_{0}$ is the baseline year (1970 in this case), $w_{i n d,-k, t}$ is the average national (log) wage in industry ind and period $t$, excluding location $k$ from the average, $L_{i n d, k, t_{0}}$ is total employment in industry ind, in location $k$, and time $t_{0}$, and $L_{k, t_{0}}$ is total employment in location $k$ and time $t_{0}$.

The second is a measure of "labor market access" and works as an instrument for labor supply (Donaldson and Hornbeck (2016), Morten and Oliveira (2016)). The presence of migration costs implies that the labor supply to destination location $k$ depends on the ease of access to that location. Therefore, we compute labor market access to location $k$ as an inverse-bilateral-cost weighted average of the population of origin locations. More specifically,

$$
\Delta \log \mathrm{MA}_{k t}=\Delta \log \left(\sum_{j \neq k}^{J} \frac{1}{\hat{\mu}_{j k}} L_{j, t-1}\right),
$$

where $\hat{\mu}_{j k}$ is the migration costs estimated from Equation 7 , and $L_{j, t-1}$ is the size of the labor force in the previous period (agriculture and non-agriculture labor). We exclude city $k^{\prime}$ s previous population from its labor market access measure. ${ }^{40}$

Table 2 shows the estimates of $\frac{1}{\sigma}$ and $\eta$, and the estimates of $\frac{\lambda_{c}}{\sigma}$. The inverse elasticity of housing supply parameter is 0.65 . This is a somewhat low inverse elasticity, which suggests that rents do not respond much to increases in local demand for housing. It

\footnotetext{
${ }^{40}$ Appendix Figure 15 shows that both instruments are strongly associated with the endogenous variables.
} 
is, however, expected for Brazil, as most meso-regions have abundant land for housing development, with the exception of large cities like São Paulo and Rio de Janeiro. The estimates of the parameters $\lambda_{c}$ reveal that winter temperature and sunshine hours are positive amenities, whereas winter rain and summer temperature are negative amenities. It is also worth noting that the magnitude of the coefficient on winter temperature is larger than the magnitude of the coefficient on summer temperature, indicating that individuals would be willing to pay more to experience warmer winters than they would pay to enjoy cooler summers. This finding is in contrast to what studies for developed countries have reported (Sinha et al. (2018)).

\section{Climate change impact on migration and welfare}

Armed with the parameter estimates from the spatial equilibrium model we simulate the effects of climate change on migration and welfare which accounts for the changes in wages and housing prices induced by population re-sorting. We perform the simulations for two climate-change scenarios from the IPCC program: the A2 emissions scenario (pessimistic), and the B1 emissions scenario (optimistic). To run the simulations, we need estimates of all the components of the indirect utility, $v_{k s t}$, and the cost parameter, $\mu_{j k}$. One issue is that we do not have data on non-climate and sector-of-employment amenities; we, therefore, estimate their sum, $X_{k s t}$, as the residual indirect utility after netting out the utility enjoyed from climate amenities, wages, and housing prices. We use the estimates of the indirect utility for 2010 - last year available — and evaluate climate amenities at the average temperatures prevailing during the baseline period. More specifically

$$
\hat{X}_{k s, 2010}^{\text {bline }}=\hat{\delta}_{k s, 2010}-\frac{1}{\hat{\sigma}}\left(\log w_{k s, 2010}-\hat{\lambda}_{r} \log r_{k, 2010}+\hat{\lambda}_{c} C_{k}^{\text {bline }}\right) .
$$

Let $s c o$ index the climate-change scenario, where $s c o=\mathrm{A} 2, \mathrm{~B} 1$. The initial value for agriculture wages under the new climate is calculated as

$$
\log w_{k a}^{s c o}=\log w_{k a, 2010}+\log \left(1+\theta_{k}^{s c o}\right)
$$

where $\theta_{k}^{s c o}$ is the rate of change in agriculture yields computed from the GAEZ dataset. ${ }^{41}$ The initial value for non-agriculture wages is $\log w_{k m}^{s c o}=\log w_{k m, 2010}$, since we assume that climate does not impact the non-agriculture sector. The indirect utility then is derived for

\footnotetext{
${ }^{41}$ Using Equation 6, we calculate $\theta_{k}^{s c o}=\left(\right.$ yields $\left.{ }_{k}^{s c o}-y_{\text {ields }}^{\text {bline }}\right) / y$ ield $s_{k}^{\text {bline }}$.
} 
each scenario as

$$
\hat{\delta}_{k s}^{s c o}=\frac{1}{\hat{\sigma}}\left(\log w_{k s}^{s c o}-\hat{\lambda}_{r} \log r_{k}+\hat{\lambda}_{c} C_{k}^{s c o}+\hat{X}_{k s, 2010}^{\text {bline }}\right)
$$

From the gravity equation for migration flows, we calculate bilateral migration costs as

$$
\hat{\mu}_{j k}^{s c o}=\frac{1}{\hat{\sigma}}\left(\hat{\mu}_{f} \mathbb{1}\{j \neq k\}+\hat{\mu}_{d} D_{j k}+\hat{\mu}_{c} C_{j k}\right) .
$$

Finally, the counterfactual bilateral migration probabilities are given by

$$
\hat{\pi}_{j k s}^{s c o}=\frac{\exp \left(\hat{\delta}_{k s}^{s c o}-\hat{\mu}_{j k}^{s c o}\right)}{\sum_{q \in\{a, m\}} \sum_{l=1}^{J} \exp \left(\hat{\delta}_{l q}^{s c o}-\hat{\mu}_{j l}^{s c o}\right)} .
$$

With these equations at hand, we proceed to simulate the impact of climate change on the economy. Faced with new climate conditions, some workers respond to changes in amenities and agriculture wages by choosing a different location and sector of employment. As migration takes place, general-equilibrium forces spur adjustments in wages in both sectors and rental prices. The new prices induce additional migration and, consequently, further changes in wages and rents. A new equilibrium is reached when migration ceases and population converges. ${ }^{42}$

After we solve for the new equilibrium quantities, we calculate the counterfactual aggregate migration rates under each scenario as

$$
\text { Migration rate } \text { reo }^{s c o}=1-\frac{\sum_{s \in\{a, m\}} \sum_{k=1}^{J} \operatorname{Pop}_{k, 2005} \hat{\pi}_{k k s}^{s c o}}{\sum_{k=1}^{J} \operatorname{Pop}_{k, 2005}}
$$

where $\hat{\pi}_{k k s}^{s c o}$ is the fraction of location $k^{\prime}$ s population that chooses not to out-migrate. We assume the meso-region population distribution in place five years prior to the 2010 census because we estimate five-year migration probabilities. ${ }^{43}$ From Equation 10, the simulated

${ }^{42}$ We use the following equations to update wages and rents in each iteration $i$

$$
\log w_{k s, i+1}=w_{k s, 0}^{r e s}+\hat{\gamma}_{s} \log L_{k s, i}
$$

and

$$
\log r_{k, i+1}=r_{k, 0}^{r e s}+\hat{\eta} \log \left(\sum_{s \in\{a, m\}} w_{k s, i} L_{k s, i}\right),
$$

where $w_{k s, 0}^{r e s}=\log w_{k s, 0}-\hat{\gamma}_{s} \log L_{k s, 0}$ and $r_{k, 0}^{r e s}=\log r_{k, 0}-\hat{\eta} \log \left(\sum_{s \in\{a, m\}} w_{k s, 0} L_{k s, 0}\right)$; the initial values, indexed by 0 , are the ones we observe in the data.

${ }^{43} \hat{\pi}_{k k s}^{s c o}=\frac{\exp \left(\hat{\delta}_{k s}^{s c o}\right)}{\sum_{q \in\{a, m\}} \sum_{l=1}^{J} \exp \left(\hat{\delta}_{l q}^{s c o}-\hat{\mu}_{k l}^{s c o}\right)}$. 
impact of climate change on migration is calculated as the percent change relative to the baseline migration rate: (Migration rate ${ }^{s c o}$ - Migration rate ${ }^{\text {bline }}$ )/Migration rate ${ }^{\text {bline }}$.

We conduct three experiments. The first experiment assumes that temperature changes only impact the amenity value of locations; the second postulates that only agriculture wages are affected; and the third experiment assumes both city amenity value and agriculture wages are impacted by climate change.

Table 3 reports the results from the simulations. Columns (1) and (3) present the results from our benchmark model with costly migration and general equilibrium effects. The third experiment indicates that under scenario A2 the migration rate is $5.79 \%$ higher than the migration rate under contemporaneous climate. The increase amounts to a 0.04 percentage-points increase from the baseline migration rate which, based on the projected population in 2040, translates into 929,282 more migrants. The impact on migration rate is smaller under B1 because temperature will not change as much compared to the A2 scenario. (The effect is a 0.03 percentage-points change or 678,056 additional migrants.) To underscore the importance of accounting for the change in agriculture yields we compare the numbers from the third experiment with the ones obtained under the first experiment. The increase in migration rates is considerably smaller (about $50 \%$ lower under A2 and $70 \%$ under B1). Also important to note is that the share of employment in agriculture is impacted by climate change ( 20 to $24 \%$ lower under future climate). The effect is mostly due to the loss in agriculture yields predicted for many parts of the country.

Columns (2) and (4) present the changes in migration rates and agriculture shares when we shut down the labor and housing markets. When wages and rents are not allowed to respond to the inflow and outflow of workers, the increase in migration due to climate change is overstated $(9.37 \%$ under $\mathrm{A} 2$ and $7.91 \%$ under $\mathrm{B} 1)$, pointing to the importance of factoring in the rise in the cost of living and reductions in wages caused by population re-sorting.

We check the robustness of our results to a different specification for climate amenities in the indirect utility function. Appendix Table 2 displays the parameter estimates of a model that features polynomials of degree three in summer and winter temperatures; Appendix Table 3 shows the simulations assuming the new specification. We still conclude that aggregate migration rate increases under both climate-change scenarios.

Next we assess the impact on the regional distribution of the population and welfare. The IBGE groups the Brazilian municipalities (and meso-regions) into five macro- 
regions. ${ }^{44}$ We calculate the share of macro-region $r$ in total population under scenario $s c o$ as

$$
\text { Population share } r_{r}^{s c o}=\sum_{k \in r} \frac{\sum_{s \in\{a, m\}} \sum_{j \in J} \operatorname{Pop}_{j, 2005} \hat{\pi}_{j k s}^{s c o}}{\sum_{k \in J} \sum_{s \in\{a, m\}} \sum_{j \in J} \operatorname{Pop}_{j, 2005} \hat{\pi}_{j k s}^{s c k}} .
$$

To calculate the impact on welfare, we rely on the distributional assumption about the idiosyncratic taste shock $\epsilon_{n k s t}$, and derive the expected utility conditional on the locational choice of individuals originated from location $j$ as ${ }^{45}$

$$
\mathrm{Utility}_{j}^{s c o}=\gamma+\log \sum_{s \in\{a, m\}} \sum_{k \in J} \exp \left(\hat{\delta}_{k s}^{s c o}+\hat{\mu}_{j k}^{s c o}\right),
$$

where $\gamma \approx 0.577$ is the Euler-Mascheroni constant. We find the welfare effect on the macro-region by averaging over the meso-regions that are part of it, weighting by the meso-region's 2005 population. The welfare impact of climate change on macro-region $r$ under scenario sco is measured as (Utility ${ }_{r}^{s c o}-$ Utility $_{r}^{\text {bline }}$ ) $/ \hat{\sigma}^{-1}$, where the change in the expected utility is converted to log wage units after dividing it by the marginal utility of wages.

Table 4 shows the simulated impact of temperature changes on population (Equation 11) and expected utility (Equation 12) for each of the five macro-regions. We focus on the third experiment which gives us the total effect. Under scenarios A2 and B1, the Southeast and the Midwest regions gain from climate change. The large welfare gain in the Southeast under A2 could be explained by winter temperatures rising more than summer temperatures (see Table 5). Additionally, agriculture yields are expected to increase slightly in meso-regions that are part of the Southeast and Midwest (see Figure 2), which could also account for the gains in those areas. In the North and Northeast, however, scenario A2 brings about large welfare losses; one explanation for these losses is the significant reduction in predicted agriculture yields in these regions (see Figure 2). The simulated changes in population mirror that found for expected utility: under the A2 scenario, the Southeast and Midwest see a sizable influx of migrants, whereas the other regions lose population. Under B1 the North also becomes more attractive, possibly because some meso-regions that comprise this macro-region expect agriculture yields to go up. The South and Northeast lose their population to the other macro-regions. Timmins

\footnotetext{
${ }^{44}$ The 135 meso-regions are grouped into five macro-regions, which are: North (NO), Northeast (NE), Southeast (SE), South (SO), and Midwest (MW). The grouping of meso-regions into macro-regions is depicted in Appendix Figure 16.

${ }^{45} \mathrm{An}$ individual's utility from their chosen location is calculated after integrating out over the distribution of the idiosyncratic taste shock, $\epsilon$. See Appendix A.5 for details on the derivation.
} 
(2007) does not assess changes in population, but he finds similar results for welfare after employing a different estimation strategy and data from alternative time periods: positive welfare effects in the South and negative effects in the North.

We now look at how climate change affects the regional flow of migrants. To that end, we take the projected 2040 meso-region population as our initial population distribution, and calculate the counterfactual five-year migration flows using the equilibrium migration probabilities under scenarios A2 and B1: Migration flow ${ }_{j k}^{s c o}=\sum_{s \in\{a, m\}} \operatorname{Pop}_{2040, k} \hat{\pi}_{j k s}^{s c o}{ }^{\cdot} 6$ We then take the sum of these flows across the meso-regions that compose a macro-region origin-destination pair, $r$ and $v$ :

$$
\text { Migration flow }{ }_{r v}^{s c o}=\sum_{j \in r} \sum_{k \in v} \text { Migration flow }_{j k}^{s c o}
$$

Table 6 shows the absolute change in the region-to-region flow of migrants (Equation 13) for scenarios A2 and B1 relative to the baseline climate. The counterfactual regional migration flows indicate that an additional 530,000 people migrate to another macro-region between 2040 and 2045 as a result of climate-change scenario A2 (the number is 266,000 under B1). The Northeast, one of the poorest, is the region that contributes the most to the rise in the number of migrants: an additional 616,000 migrants leave the region in a five-year period under scenario A2 compared to the baseline $(715,000$ under B1). The Southeast, the richest region in the country, receives a larger inflow of people from all the other regions under both scenarios (an additional 805,000 migrants under A2 scenario and 597,000 under B1). The largest chunk of the inflow of migrants to the Southeast comes from the Northeast: while 405,000 more migrants under A2 (393,000 under B1) are expected in the Southeast from the Northeast, 261,000 fewer migrants under A2 (266,000 under B1) are expected in the Northeast from the Southeast. The Midwest is another region whose inflow (outflow) of migrants from all regions (except the Southeast) is expected to increase (decrease). Like the Southeast, the net flow of migration from the Northeast will be higher: 122,000 more people are expected to migrate from the Northeast under A2 (140,000 more under B1) but 64,000 fewer people from the Midwest will migrate to that region under A2 (67,000 fewer under B1). The Midwest is Brazil's current agriculture frontier, and potential agriculture yields are predicted to rise in many of its meso-regions particularly under the A2 scenario (see Figure 2).

\footnotetext{
${ }^{46}$ We update the 2017 meso-region population estimates from the IBGE using state-level population growth rates from 2017-2030 (also provided by the IBGE) and national growth rates from 2030-2040 (2017 Revision of World Population Prospects, provided by the United Nations).
} 
The last three panels of Table 6 show the impact on regional population (as a percentage of the 2040 projected population), out-migration, and in-migration rates. The numbers confirm the results from Table 4 that the Northeast is the biggest loser: the region loses about $1.5 \%$ of its population to other regions under A2 (1.8\% under B1); $63 \%$ of the fall in Northeast's population is due to the increase in out-migration (the remainder is due to the decrease in in-migration). The Southeast and Midwest are the winners. Under scenario A2 there is a $1.4 \%$ increment in the Southeast's population (about $60 \%$ due to increase in in-migration rate), and a $1.2 \%$ increment in the Midwest's population (90\% due to increase in in-migration). Both the North and South are expected to lose population but the magnitude of the loss varies considerably across climate-change scenarios. As Figure 2 suggests, agriculture yields in the North are predicted to fall much more under the A2 scenario, which could explain the discrepancy.

\section{Concluding Remarks}

This paper fits into a large literature that assesses the economic consequences of environmental changes. In particular, we ask if long-term changes in the climate induce migration and re-shape the spatial distribution of the labor force in Brazil. In doing so, we propose and estimate a spatial equilibrium model with costly migration in which the climate affects the individuals' choice of location through the usual location-amenity channel and a new channel working through changes in agriculture productivity. The model allows us to answer those questions while accounting for general equilibrium effects on labor and housing markets.

Our main conclusion is that under future climate conditions the Northeast, one of the least developed regions, would lose population and be worse off; on the other hand, the richest and most populated region, the Southeast, would see substantial positive effects on its population size and welfare. Because of the potential deepening of the existing south-north inequality in Brazil, our results can be used to identify the more vulnerable populations in order to promote local public policies to prepare the regions for population inflows and outflows and for negative agriculture shocks. Our study also underscores that migration could be used as an adaptation instrument to deal with climate change. 


\section{References}

Albouy, D., 2009. The Unequal Geographic Burden of Federal Taxation. Journal of Political Economy 117 (4), 635-667.

Albouy, D., Graf, W., Kellogg, R., Wolff, H., 2016. Climate Amenities, Climate Change, and American Quality of Life. Journal of the Association of Environmental and Resource Economists 3 (1), 205-246.

Baez, J., Caruso, G., Mueller, V., Niu, C., 2017. Heat Exposure and Youth Migration in Central America and the Caribbean. American Economic Review: Papers \& Proceedings 107 (5), 446-450.

Barrios, S., Bertinelli, L., Strobl, E., 2006. Climatic change and rural-urban migration: The case of sub-Saharan Africa. Journal of Urban Economics 60 (3), 357-371.

Bartik, T. J., 1991. Who Benefits from State and Local Economic Development Policies? Books from Upjohn Press.

Bayer, P., Ferreira, F., McMillan, R., 2007. A Unified Framework for Measuring Preferences for Schools and Neighborhoods. Journal of Political Economy 115 (4), 588-638.

Bayer, P., Keohane, N., Timmins, C., 2009. Migration and hedonic valuation: The case of air quality. Journal of Environmental Economics and Management 58 (1), 1-14.

Berry, S., Levinsohn, J., Pakes, A., 2004. Differentiated Products Demand Systems from a Combination of Micro and Macro Data: The New Car Market. Journal of Political Economy 112 (1), 68-105.

Blomquist, G., Berger, M., Hoehn, J., 1988. New estimates of quality of life in urban areas. The American Economic Review 78 (1), 89-107.

Burke, M., Hsiang, S. M., Miguel, E., 2015. Global non-linear effect of temperature on economic production. Nature 527 (7577), 235-239.

Chou, S. C., Lyra, A., Mourão, C., Dereczynski, C., Pilotto, I., Gomes, J., Bustamante, J., Tavares, P., Silva, A., Rodrigues, D., Campos, D., Chagas, D., Sueiro, G., Siqueira, G., Marengo, J., 2014a. Assessment of Climate Change over South America under RCP 4.5 and 8.5 Downscaling Scenarios. American Journal of Climate Change 03 (05), 512-527.

Chou, S. C., Lyra, A., Mourão, C., Dereczynski, C., Pilotto, I., Gomes, J., Bustamante, J., Tavares, P., Silva, A., Rodrigues, D., Campos, D., Chagas, D., Sueiro, G., Siqueira, G., Nobre, P., Marengo, J., 2014b. Evaluation of the Eta Simulations Nested in Three Global Climate Models. American Journal of Climate Change 03 (05), 438-454.

Collins, W. J., Bellouin, N., Doutriaux-Boucher, M., Gedney, N., Halloran, P., Hinton, T., Hughes, J., Jones, C. D., Joshi, M., Liddicoat, S., Martin, G., O'Connor, F., Rae, J., Senior, C., Sitch, S., Totterdell, I., Wiltshire, A., Woodward, S., 2011. Development and evaluation of an Earth-System model âĂŞ HadGEM2. Geoscientific Model Development 4 (4), 1051-1075. 
Cragg, M., Kahn, M., 1997. New Estimates of Climate Demand: Evidence from Location Choice. Journal of Urban Economics 42 (2), 261-284.

Cropper, M. L., Sinha, P., 2013. The Value of Climate Amenities: Evidence from U.S. Migration Decisions. NBER working paper \#18756.

da Cunha, D. A., Coelho, A. B., Féres, J. G., 2014. Irrigation as an adaptive strategy to climate change: an economic perspective on Brazilian agriculture. Environment and Development Economics 20 (01), 57-79.

Dell, M., Jones, B. F., Olken, B. A., 2012. Temperature Shocks and Economic Growth: Evidence from the Last Half Century. American Economic Journal: Macroeconomics 4 (3), 66-95.

Dell, M., Jones, B. F., Olken, B. A., 2014. What Do We Learn from the Weather? The New Climate-Economy Literature. Journal of Economic Literature 52 (3), 740-798.

Diamond, R., 2016. The Determinants and Welfare Implications of US Workers' Diverging Location Choices by Skill: 1980-2000. American Economic Review Forthcomin.

Donaldson, D., Hornbeck, R., 2016. Railroads and American Economic Growth: A "Market Access" Aproach. Quarterly Journal of Economics (August), 799-858.

Drabo, A., Mbaye, L. M., 2011. Climate Change , Natural Disasters and Migration : An Empirical Analysis in Developing Countries. IZA Discussion Papers (5927).

Findley, S. E., 1994. Does drought increase migration? A study of migration from rural Mali during the 1983-1985 drought. The International Migration Review 28 (3), 539-553.

Fischer, G., Nachtergaele, F. O., Prieler, S., Teixeira, E., Toth, G., van Velthuizen, H., Verelst, L., Wiberg, D., 2012. Global Agro-ecological Zones (GAEZ): Model Documentation, 1-179.

Gray, C. L., Mueller, V., 2012. Natural disasters and population mobility in Bangladesh. Proceedings of the National Academy of Sciences 109 (16), 6000-6005.

Haas, T. C., 1990. Kriging and automated variogram modeling within a moving window. Atmospheric Environment. Part A. General Topics 24 (7), 1759-1769.

Hornbeck, R., 2012. The enduring impact of the American Dust Bowl: Short- and long-run adjustments to environmental catastrophe. American Economic Review 102 (4), 14771507.

Klaiber, H. A., Phaneuf, D. J., 2010. Valuing open space in a residential sorting model of the Twin Cities. Journal of Environmental Economics and Management 60 (2), 57-77.

Maddison, D., 2003. The amenity value of the climate: the household production function approach. Resource and Energy Economics 25 (2), 155-175. 
Maddison, D., Bigano, A., 2003. The Amenity Value of the Italian Climate. Journal of Environmental Economics and Management 45 (2), 319-332.

Mangum, K., 2015. Cities and Labor Market Dynamics. Ph.D. thesis, Duke University.

Marchiori, L., Maystadt, J. F., Schumacher, I., 2012. The impact of weather anomalies on migration in sub-Saharan Africa. Journal of Environmental Economics and Management 63 (3), 355-374.

Marchiori, L., Schumacher, I., 2011. When nature rebels: International migration, climate change, and inequality. Journal of Population Economics 24 (2), 569-600.

Martin, M., Billah, M., Siddiqui, T., Abrar, C., Black, R., Kniveton, D., 2014. Climaterelated migration in rural Bangladesh: a behavioural model. Population and Environment 77 (1), 85-110.

McFadden, D., 1973. Conditional Logit Analyisis of Qualitative Choice Behavior. In: P. Zarembka (Ed.), In Frontiers in Econometrics. Academic Press, pp. 105-142.

Morten, M., Oliveira, J., 2016. The Effects of Roads on Trade and Migration: Evidence from a Planned Capital City. Unpublished Manuscript.

Mueller, V. A., 2005. Valuing Climate Amenities in Brazil Using a Hedonic Pricing Framework. Ph.D. thesis, University of Maryland.

Partridge, M. D., Feng, B., Rembert, M., 2017. Improving climate-change modeling of US migration. American Economic Review 107 (5), 451-455.

Rehdanz, K., Maddison, D., 2009. The Amenity Value of Climate to Households in Germany. Oxford Economic Papers 61 (1), 150-167.

Saldaña-Zorrilla, S. O., Sandberg, K., 2009. Impact of climate-related disasters on human migration in Mexico: A spatial model. Climatic Change 96 (1), 97-118.

Seo, S. N., McCarl, B. a., Mendelsohn, R., 2010. From beef cattle to sheep under global warming? An analysis of adaptation by livestock species choice in South America. Ecological Economics 69 (12), 2486-2494.

Seo, S. N., Mendelsohn, R., 2008. Measuring impacts and adaptations to climate change: A structural Ricardian model of African livestock management. Agricultural Economics 38 (2), 151-165.

Sinha, P., Caulkins, M. L., Cropper, M. L., 2018. Household location decisions and the value of climate amenities. Journal of Environmental Economics and Management, 130.

Taraz, V., 2017. Adaptation to climate change: Historical evidence from the Indian monsoon. Environment and Development Economics 22 (5), 517-545. 
Timmins, C., 2007. If you cannot take the heat, get out of the cerrado... Recovering the equilibrium amenity cost of nonmarginal climate change in Brazil. Journal of Regional Science 47 (1), 1-25.

Watanabe, M., Suzuki, T., O'Ishi, R., Komuro, Y., Watanabe, S., Emori, S., Takemura, T., Chikira, M., Ogura, T., Sekiguchi, M., Takata, K., Yamazaki, D., Yokohata, T., Nozawa, T., Hasumi, H., Tatebe, H., Kimoto, M., 2010. Improved climate simulation by MIROC5: Mean states, variability, and climate sensitivity. Journal of Climate 23 (23), 6312-6335.

Xavier, A. C., King, C. W., Scanlon, B. R., 2016. Daily gridded meteorological variables in Brazil (1980-2013). International Journal of Climatology 36, 2644-2659. 


\section{Figures and Tables}

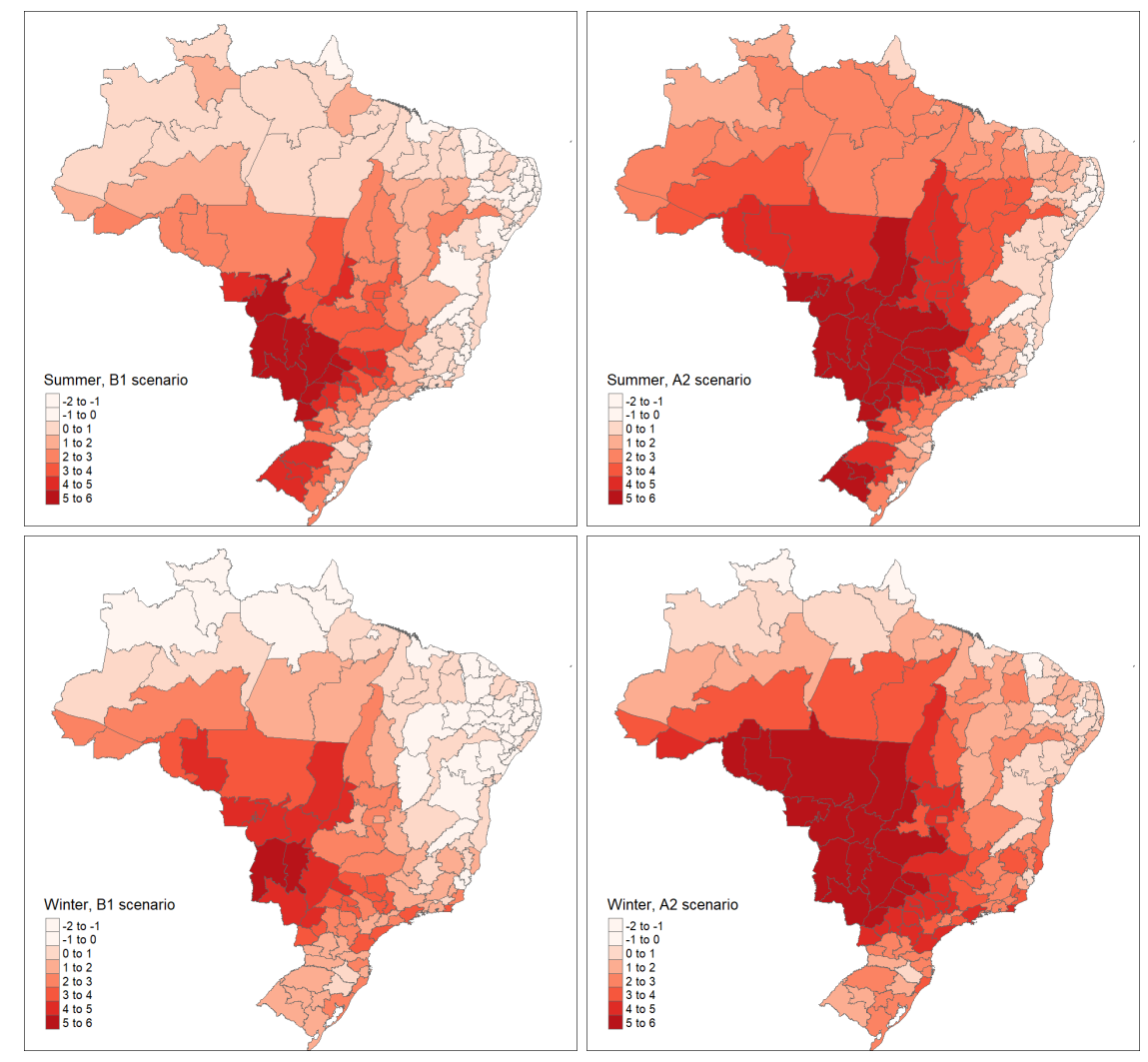

Figure 1: Change in temperature (in degrees Celsius) in summer and winter, B1 and A2 scenarios

Notes: Change in temperature relative to the baseline. Baseline climate covers the 1961-1990 period; climate change forecast covers the 2041-2070 period. Data source: CPTEC/INPE. 

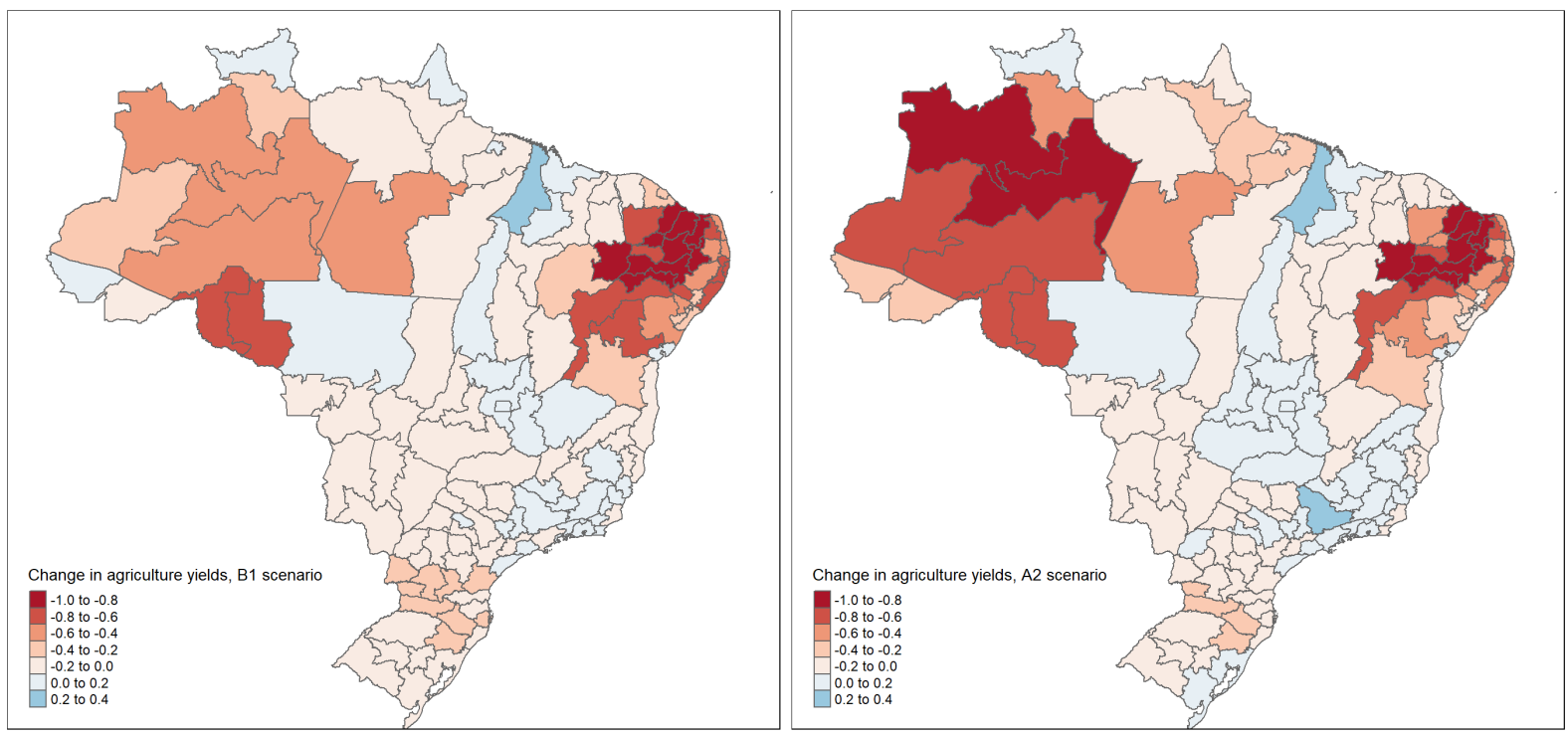

Figure 2: Change in log agriculture yields, B1 and A2 scenarios

Notes: Agriculture yields (in USD/ha) calculated as the weighted sum of potential crop yields obtained from the GAEZ dataset; weight is the share of the crop in total crop area over the 1990-2010 period. Baseline climate covers the 1961-1990 period; climate change forecast covers the 2041-2070 period. Data source: GAEZ and PAM-IBGE. 


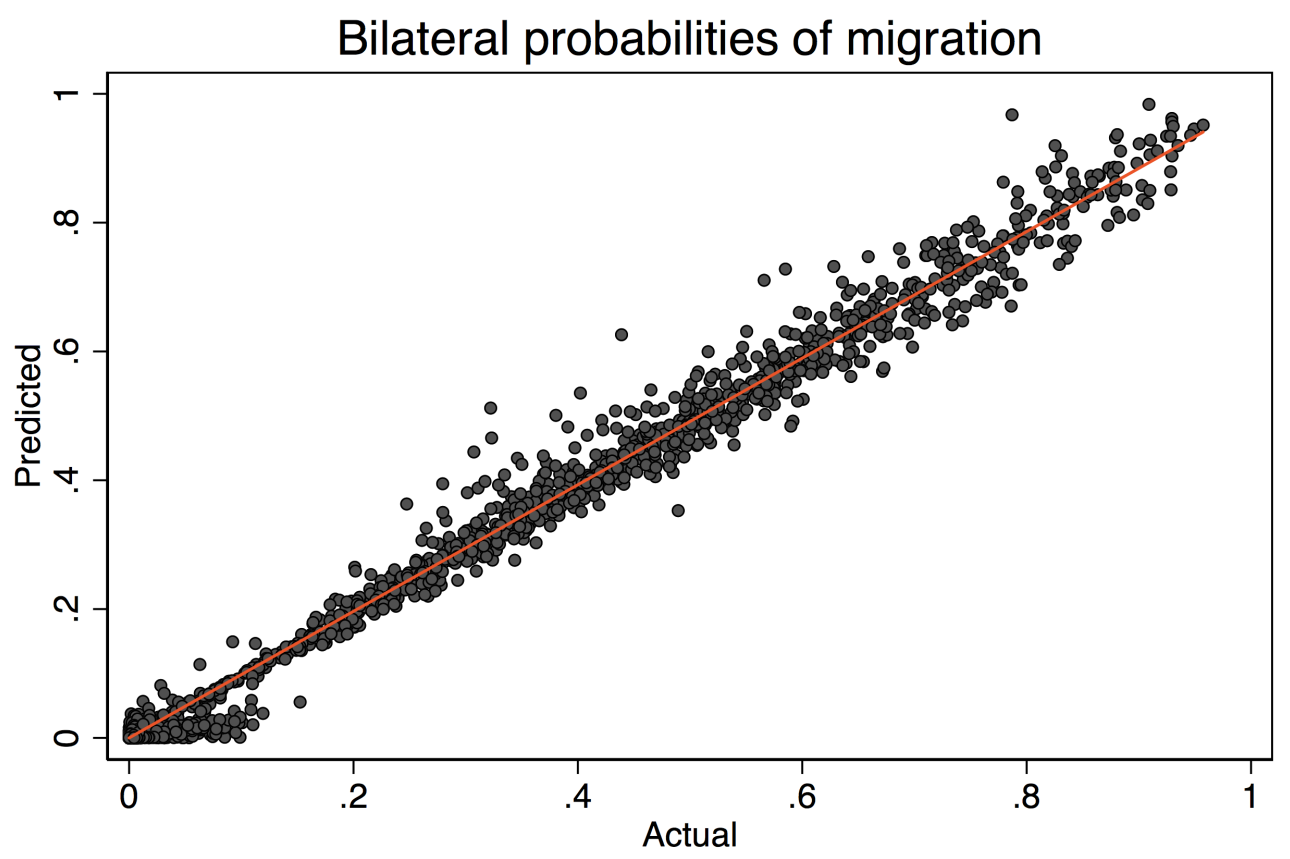

R-squared: 0.9937

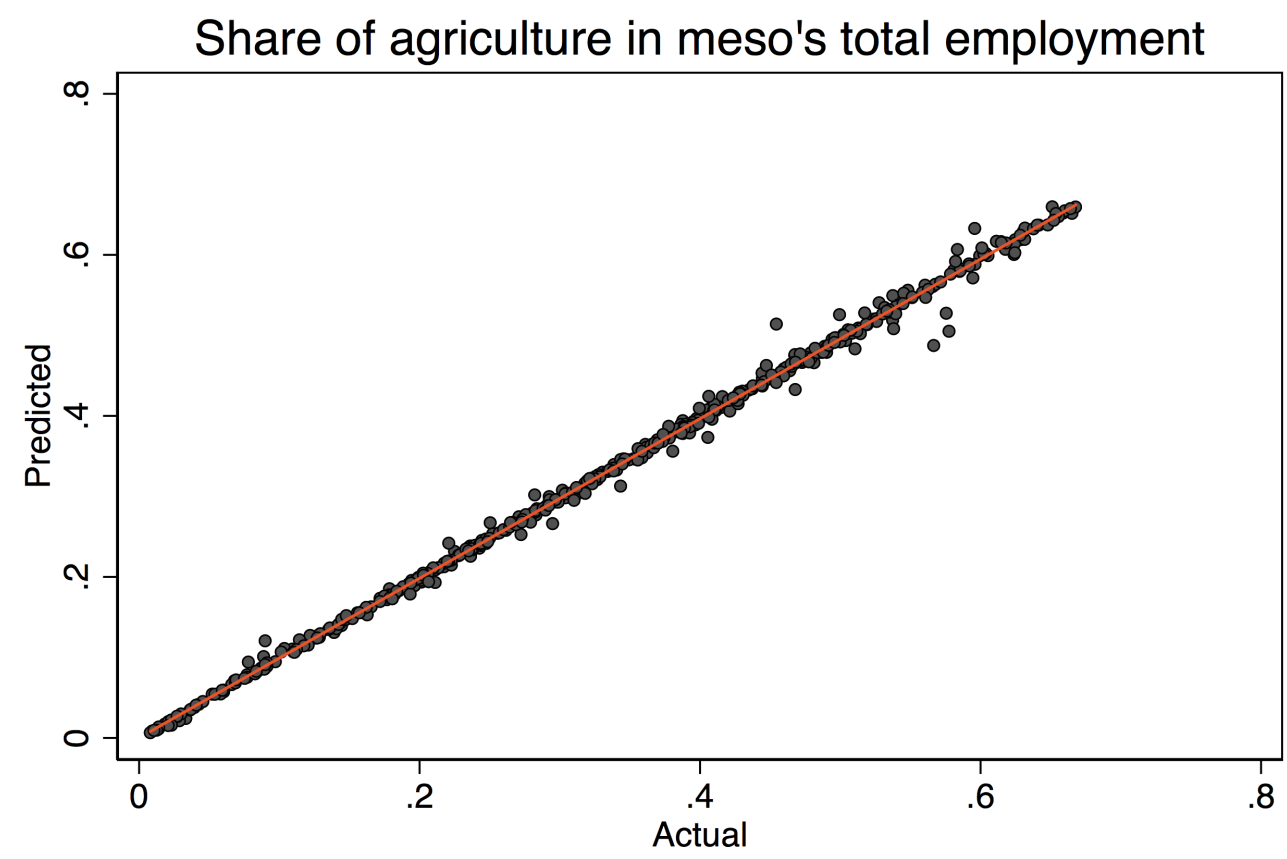

R-squared: 0.9978

Figure 3: Model's goodness of fit: bilateral migration probabilities and agriculture share in total employment

Notes: The first figure depicts the bilateral migration probabilities; each point is an origin-destination-sectoryear observation (145,800 observations total). The second figure shows agriculture employment shares; each point is a destination-year observation (540 observations total). Data source: Population Census, 19802010. 
Table 1: Estimates of cost parameters

\begin{tabular}{lcc}
\hline & $(1)$ & $(2)$ \\
& $\mathrm{b} / \mathrm{se}$ & $\mathrm{b} / \mathrm{se}$ \\
\hline $\mathbb{1}\{j \neq k\}$ & $4.93^{* * *}$ & $4.84^{* * *}$ \\
& $(0.033)$ & $(0.035)$ \\
Distance $_{j k}[2,4)$ & $1.07^{* * *}$ & $1.01^{* * *}$ \\
& $(0.045)$ & $(0.044)$ \\
Distance $_{j k}[4,8)$ & $2.39^{* * *}$ & $2.31^{* * *}$ \\
& $(0.047)$ & $(0.047)$ \\
Distance $_{j k}[8,16)$ & $3.37^{* * *}$ & $3.26^{* * *}$ \\
& $(0.054)$ & $(0.057)$ \\
Distance $_{j k}[16,32)$ & $3.69^{* * *}$ & $3.57^{* * *}$ \\
& $(0.054)$ & $(0.077)$ \\
Distance $_{j k}[32$, max $)$ & $5.15^{* * *}$ & $5.05^{* * *}$ \\
& $(0.072)$ & $(0.088)$ \\
$\left|T_{j}-T_{k}\right|\left[1^{o}, 2^{o}\right)$ & & $0.30^{* * *}$ \\
& & $(0.037)$ \\
$\left|T_{j}-T_{k}\right|\left[2^{o}, 3^{o}\right)$ & & $0.33^{* * *}$ \\
& & $(0.054)$ \\
$\left|T_{j}-T_{k}\right|\left[3^{o}, 4^{o}\right)$ & & $0.17^{* *}$ \\
& & $(0.076)$ \\
$\left|T_{j}-T_{k}\right|\left[4^{o}\right.$, max $)$ & & $0.20^{* * *}$ \\
& & $(0.074)$ \\
No. meso-sec pairs & 145800 & 145800 \\
Migration rate & 0.076 & 0.076 \\
Dist migrated $_{\text {Avg. diff temp }}$ & 6.50 & 6.50 \\
\hline & 0.29 & 0.29 \\
\hline
\end{tabular}

Notes: Parameters generated using Poisson ML estimator. Estimating sample consists of $135 \times 135 \times 2 \times$ $4=145,800$ origin-destination-sectoryear observations. $\mathbb{1}\{j \neq k\}$ is an indicator for whether the destination mesoregion is different from the origin mesoregion; Distance $_{j k}$ is the Euclidean distance, in $100 \mathrm{~km}$; The omitted category is Distance $_{j k}[0,2) .\left|T_{j}-T_{k}\right|$ is the absolute difference in average of monthly temperatures (in ${ }^{\circ} \mathrm{C}$ ) measured 10 years prior to the census; the omitted category is $\mid T_{j}-$ $T_{k} \mid\left[0^{\circ}, 1^{o}\right)$. Data source: CPTEC/INPE and Population Census, 1980-2010. 
Table 2: Structural coefficient estimates

\begin{tabular}{|c|c|}
\hline & $\begin{array}{c}\text { Parameters } \\
(1) \\
\text { b/se }\end{array}$ \\
\hline \multicolumn{2}{|l|}{ Equation 1: housing supply } \\
\hline$\eta$ & $\begin{array}{c}0.65^{* * *} \\
(0.21)\end{array}$ \\
\hline \multicolumn{2}{|l|}{ Equation 2: indirect utility } \\
\hline$\sigma^{-1}$ & $\begin{array}{l}2.16^{* * *} \\
(0.74)\end{array}$ \\
\hline$\sigma^{-1} \lambda_{\text {summer temp }}$ & $\begin{array}{l}-0.22^{* * *} \\
(0.081)\end{array}$ \\
\hline$\sigma^{-1} \lambda_{\text {winter temp. }}$ & $\begin{array}{l}0.29 * * * \\
(0.081)\end{array}$ \\
\hline$\sigma^{-1} \lambda_{\text {summer rain }}$ & $\begin{array}{l}-0.0022 \\
(0.0016)\end{array}$ \\
\hline$\sigma^{-1} \lambda_{\text {winter rain }}$ & $\begin{array}{c}-0.0047^{* * *} \\
(0.0017)\end{array}$ \\
\hline$\sigma^{-1} \lambda_{\text {summer sunshine }}$ & $\begin{array}{l}0.0056^{* *} \\
(0.0028)\end{array}$ \\
\hline$\sigma^{-1} \lambda_{\text {winter sunshine }}$ & $\begin{array}{l}-0.0027 \\
(0.0030)\end{array}$ \\
\hline Equation 3: labor demand & \\
\hline$\beta^{m}$ & $\begin{array}{l}-0.19 * * * \\
(0.023)\end{array}$ \\
\hline$\beta^{a}$ & $\begin{array}{l}-0.050 * * \\
(0.020)\end{array}$ \\
\hline
\end{tabular}

Notes: Estimating sample consists of $135 \times$ $2 \times 4=1,080$ destination-sector-year observations. Parameter estimates from the system of two equations obtained from a 3SLS estimator which allows for an arbitrary error correlation. Endogenous employment and wages instrumented by Bartik shocks and inverse-cost weighted market access (interacted with sector of employment). Economic and climate variables are in first differences, available for years 2010 2000, 2000-1991, and 1991-1980. Summer and winter temperatures are 10-year averages prior to the census year. Additional controls (sector fixed effects and state-year fixed effects) included but not reported. Data source: Population Census, 1980-2010. 
Table 3: Simulated impact of climate change on aggregate migration rates

\begin{tabular}{lcccc}
\hline & A2 scenario & \multicolumn{3}{c}{ B1 scenario } \\
& $(1)$ & $(2)$ & $(3)$ & $(4)$ \\
GE & PE & GE & PE \\
\hline \multicolumn{4}{c}{ Experiment 1: climate impacts city amenity value } \\
$\Delta$ Migration rate (\%) & 2.85 & 6.07 & 1.24 & 4.41 \\
$\Delta$ Agric. share (\%) & -0.78 & -0.78 & -0.75 & -0.72 \\
Experiment 2: climate impacts agricultural productivity \\
$\Delta$ Migration rate (\%) & 0.86 & 1.51 & 0.80 & 1.67 \\
$\Delta$ Agric. share (\%) & -19.9 & -21.6 & -23.8 & -25.7 \\
Experiment 3: climate impacts & amenities and ag. productivity \\
$\Delta$ Migration rate (\%) & 5.79 & 9.37 & 4.23 & 7.91 \\
$\Delta$ Agric. share (\%) & -20.3 & -22.0 & -24.1 & -26 \\
\hline
\end{tabular}

Notes: Columns (1) and (3) show simulations from model with costly migration and general equilibrium effects; columns (2) and (4) show simulations from model with costly migration without general equilibrium effects. Climate change forecasts for 20412070 period. The effects represent changes relative to baseline climate, which is the long-term average over 1961-1990. Climate change scenarios: A2 (high emissions) and B1 (low emissions). Simulations use non-climate amenity levels of year 2010. Experiment 1: assumes that climate variables impact city amenity value only; experiment 2: climate variables impact agriculture productivity only; experiment 3: climate variables impact city amenity value and agriculture productivity. Data source: CPTEC/INPE, GAEZ, and 1980-2010 Population Census. 


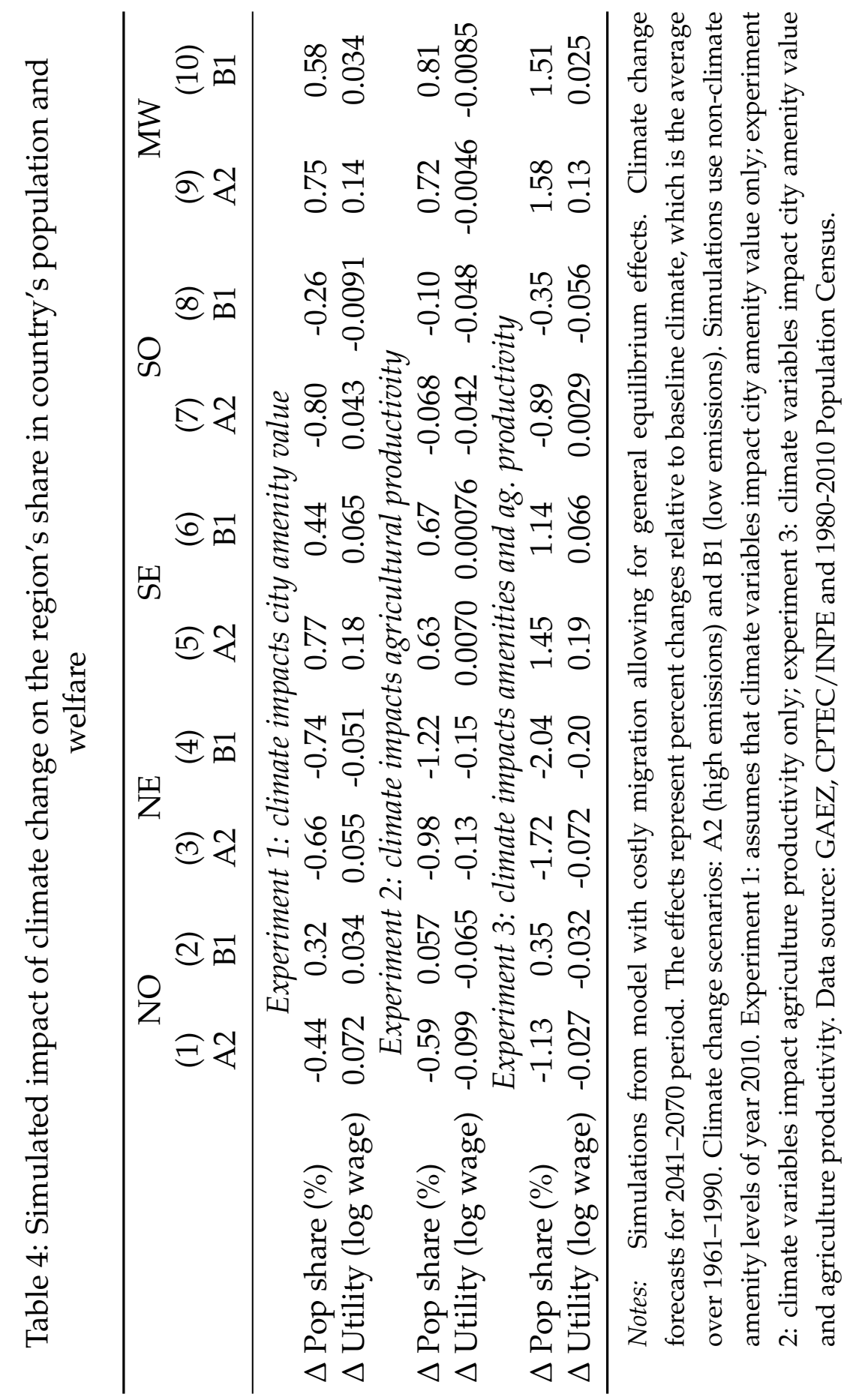


Table 5: Temperature change forecast by macro-region, weighted by 2010 population

\begin{tabular}{lccccc}
\hline & NO & NE & SE & SO & MW \\
& $(1)$ & $(2)$ & $(3)$ & $(4)$ & $(5)$ \\
& & & & \\
\hline \multicolumn{5}{c}{ A2 climate scenario } \\
Summer temperature $\left(\Delta^{\circ} C\right)$ & 2.64 & 1.15 & 2.75 & 3.58 & 6.12 \\
Winter temperature $\left(\Delta^{\circ} C\right)$ & 2.21 & 1.13 & 3.52 & 2.90 & 5.87 \\
$B 1$ climate scenario \\
Summer temperature $\left(\Delta^{\circ} C\right)$ & 1.13 & 0.18 & 1.87 & 2.94 & 4.49 \\
Winter temperature $\left(\Delta^{\circ} C\right)$ & 0.77 & -0.36 & 1.85 & 2.05 & 3.89 \\
\hline
\end{tabular}

Notes: Climate change forecasts for 2041-2070 period. Difference in temperature is relative to baseline. Baseline climate is calculated as the average over 1961-1990. Temperature changes by macro-region are weighted by 2010 population. Climate change scenarios: A2 (high emissions) and B1 (low emissions). Data source: CPTEC/INPE and Population Census. 
Table 6: Simulated impact of climate change on regional migration flows and 2040 population

\begin{tabular}{|c|c|c|c|c|c|c|c|c|c|c|}
\hline & \multicolumn{5}{|c|}{ A2 scenario } & \multicolumn{5}{|c|}{ B1 scenario } \\
\hline & (1) & (2) & (3) & $(4)$ & (5) & (6) & (7) & (8) & (9) & (10) \\
\hline & NO & NE & SE & SO & MW & $\mathrm{NO}$ & $\mathrm{NE}$ & SE & SO & MW \\
\hline \multicolumn{11}{|c|}{$\Delta 5$-year migration flows $(100,000)$} \\
\hline $\mathrm{NO}$ & -2.97 & 0.19 & 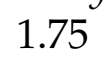 & 0.36 & 0.68 & -0.69 & -0.42 & 0.68 & 0.10 & 0.32 \\
\hline NE & 0.28 & -6.16 & 4.05 & 0.61 & 1.22 & 0.77 & -7.15 & 3.93 & 1.04 & 1.40 \\
\hline SE & -0.53 & -2.61 & 5.19 & -1.86 & -0.19 & -0.27 & -2.66 & 4.51 & -1.45 & -0.13 \\
\hline $\mathrm{SO}$ & 0.017 & -0.37 & 1.57 & -1.58 & 0.36 & 0.067 & -0.58 & 0.81 & -0.53 & 0.23 \\
\hline MW & -0.10 & -0.64 & 0.68 & -0.16 & 0.22 & 0.034 & -0.67 & 0.55 & -0.050 & 0.14 \\
\hline \multicolumn{11}{|c|}{2040 population $(1,000,000)$} \\
\hline & 19.9 & 62.0 & 95.1 & 32.5 & 18.8 & 19.9 & 62.0 & 95.1 & 32.5 & 18.8 \\
\hline \multicolumn{11}{|c|}{$\Delta$ population (\% of 2040 pop) } \\
\hline & -1.66 & -1.55 & 1.39 & \multirow{2}{*}{\multicolumn{7}{|c|}{$\Delta$ out-migration (\% of pop) }} \\
\hline & 49 & 099 & & 0.49 & $-0,12$ & 034 & & & & \\
\hline \multicolumn{11}{|c|}{$\Delta$ in-migration (\% of pop) } \\
\hline & -0.17 & -0.56 & 0.84 & -0.32 & 1.09 & 0.30 & -0.71 & 0.62 & -0.11 & 0.97 \\
\hline
\end{tabular}

Notes: Bilateral 5-year migration probabilities come from the model with costly migration and general equilibrium effects. The predicted migration flows are calculated using the projected 2040 population as initial population. The numbers reported on the first panel of the table are the changes in bilateral migration flows due to climate change relative to the baseline climate (the average climate over the 1961-1990 period). Data source: GAEZ, CPTEC/INPE and 1980-2010 Population Census. 


\section{APPENDIX: FOR ONLINE PUBLICATION ONLY}

\section{A Appendix}

\section{A.1 Figures and Tables}
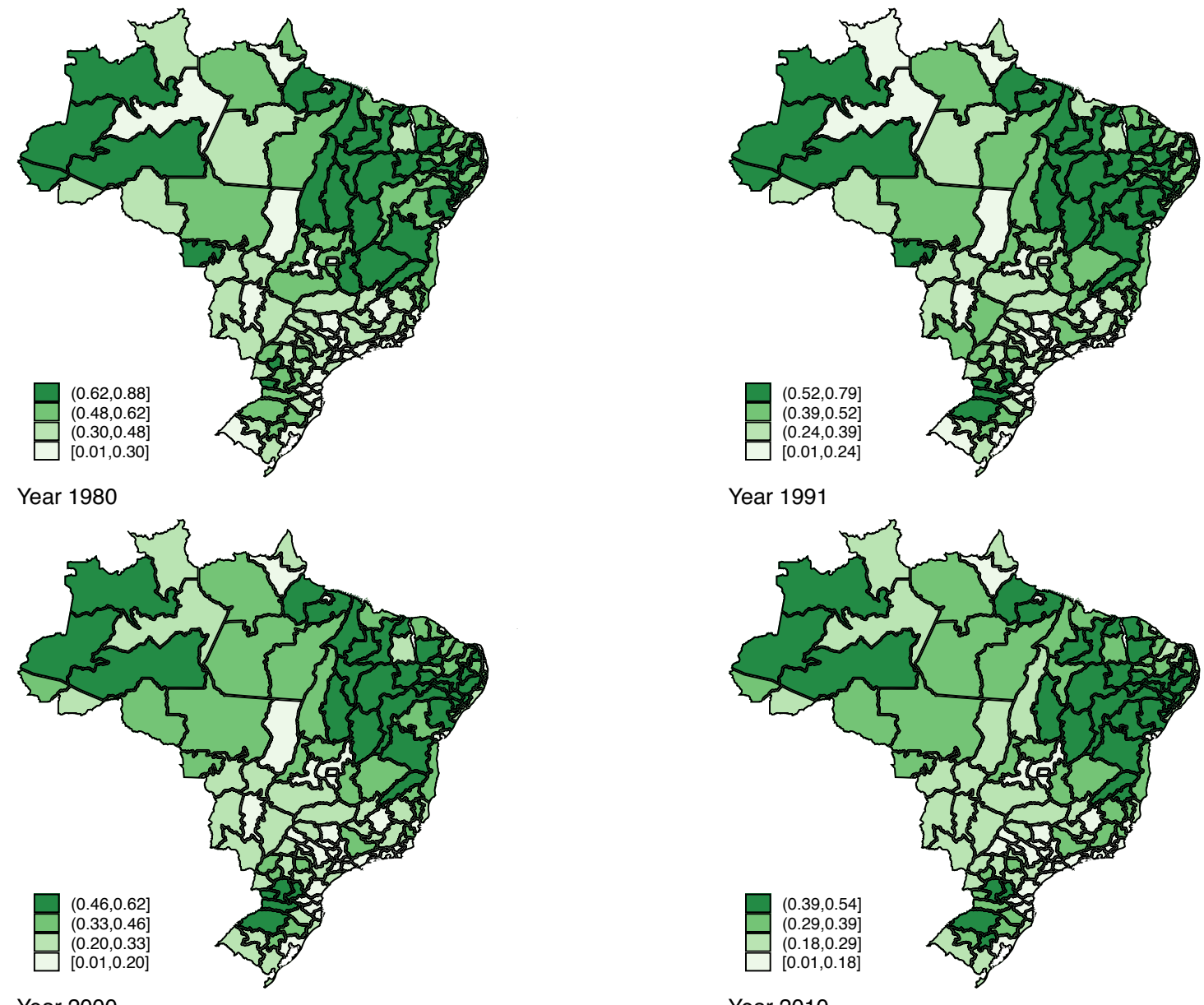

Appendix Figure 1: Share of agriculture in total employment

Notes: Data source: 1980-2010 Population Census. 

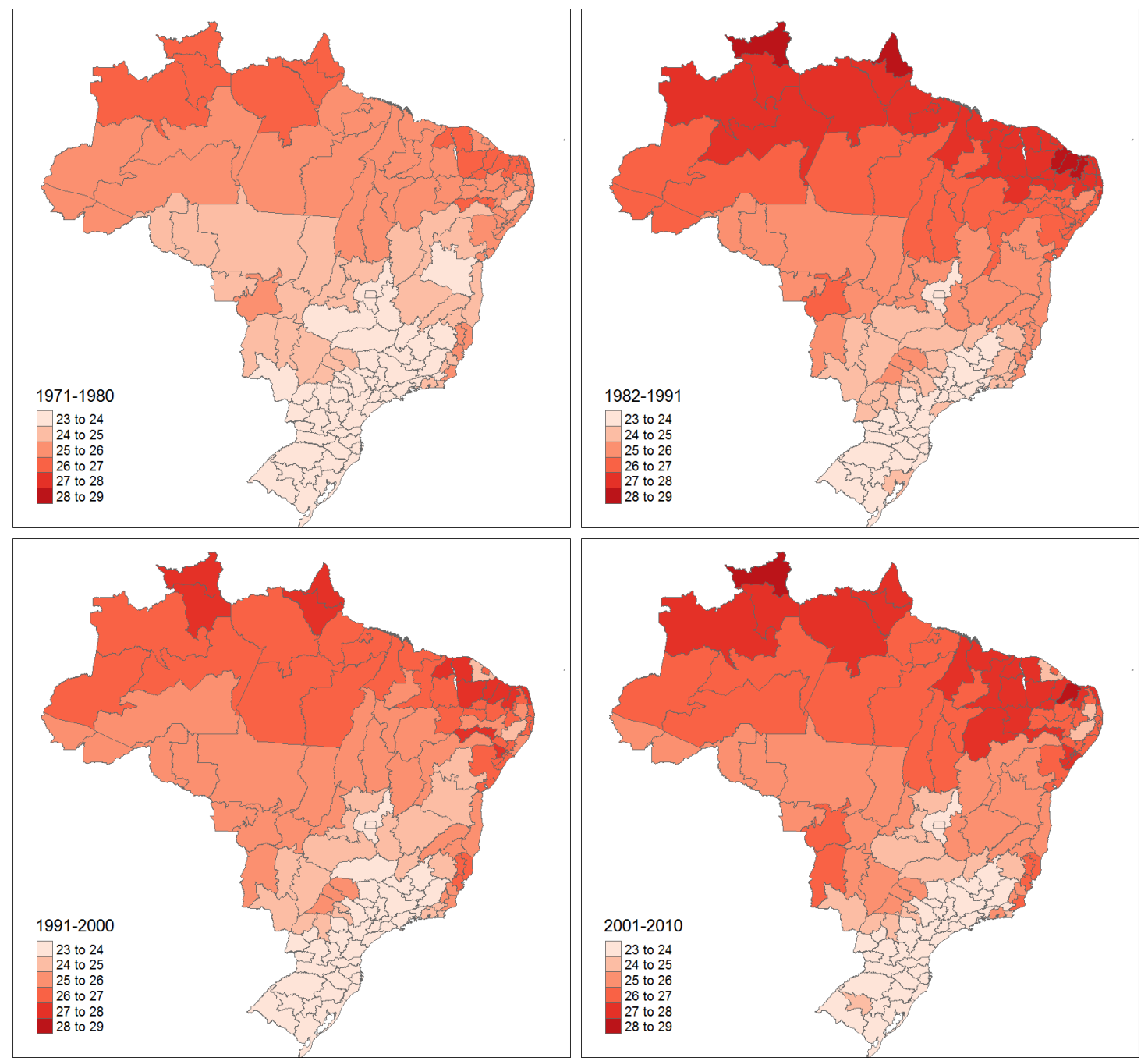

Appendix Figure 2: 10-year average temperature in summer by census year, in degrees Celsius

Notes: Daily temperatures are averaged out over the 10 years preceding the census. Data source: Brazilian Institute of Meteorology. 

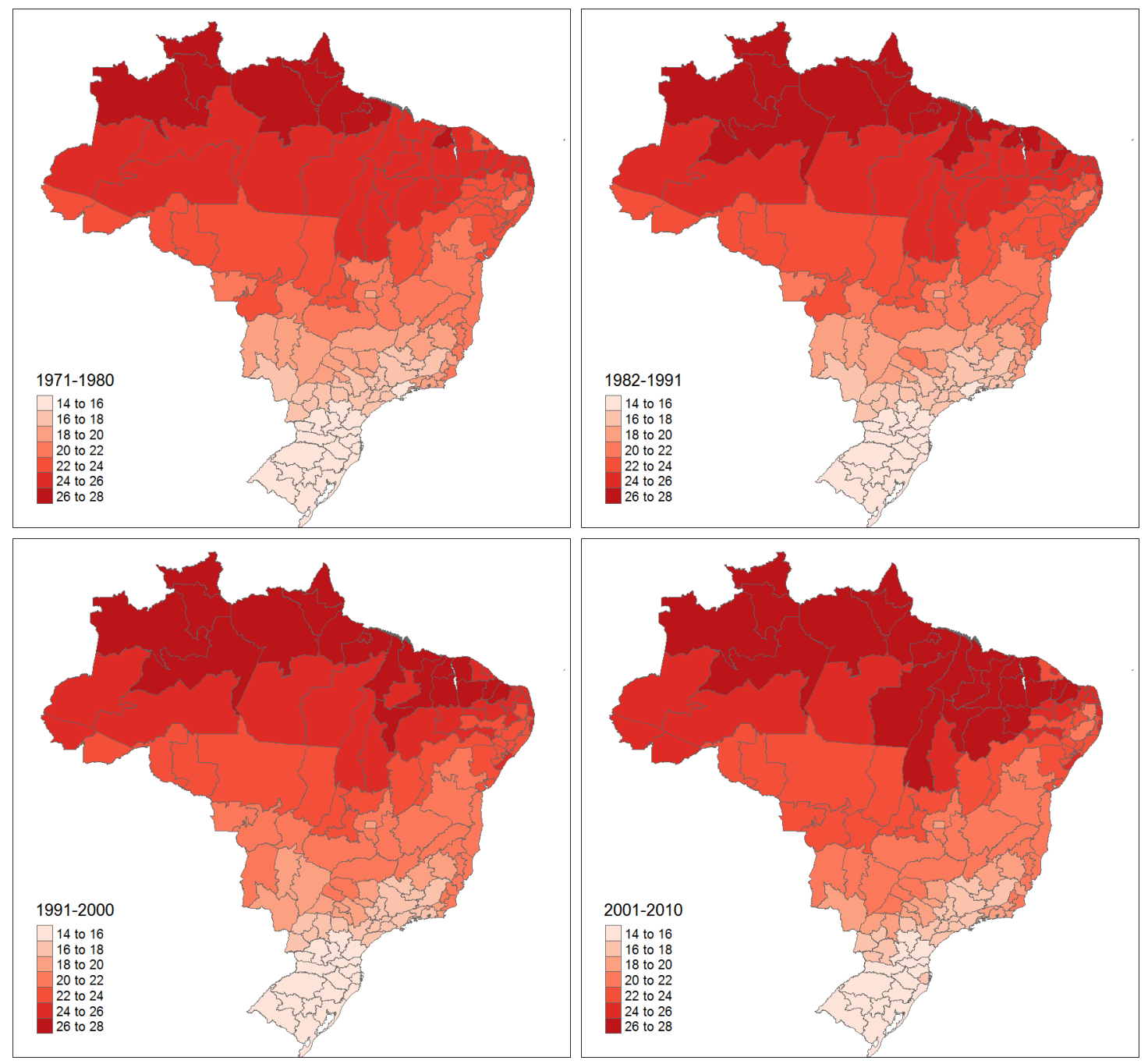

Appendix Figure 3: 10-year average temperature in winter by census year, in degrees Celsius

Notes: Daily temperatures are averaged out over the 10 years preceding the census. Data source: Brazilian Institute of Meteorology. 

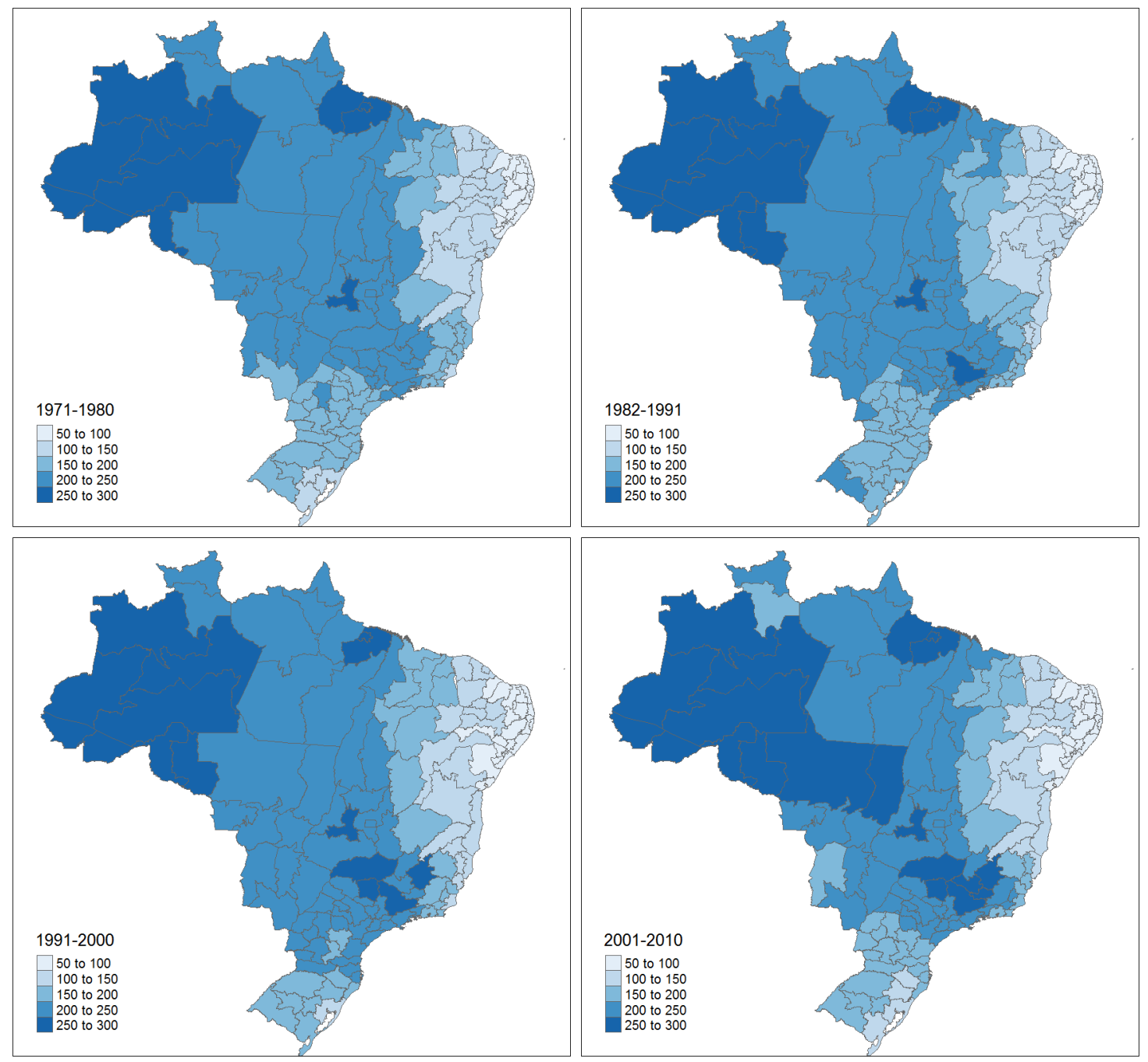

Appendix Figure 4: 10-year average rainfall in summer by census year, in $\mathrm{mm} / \mathrm{month}$

Notes: Daily rainfall is averaged out over the 10 years preceding the census. Data source: Brazilian Institute of Meteorology. 

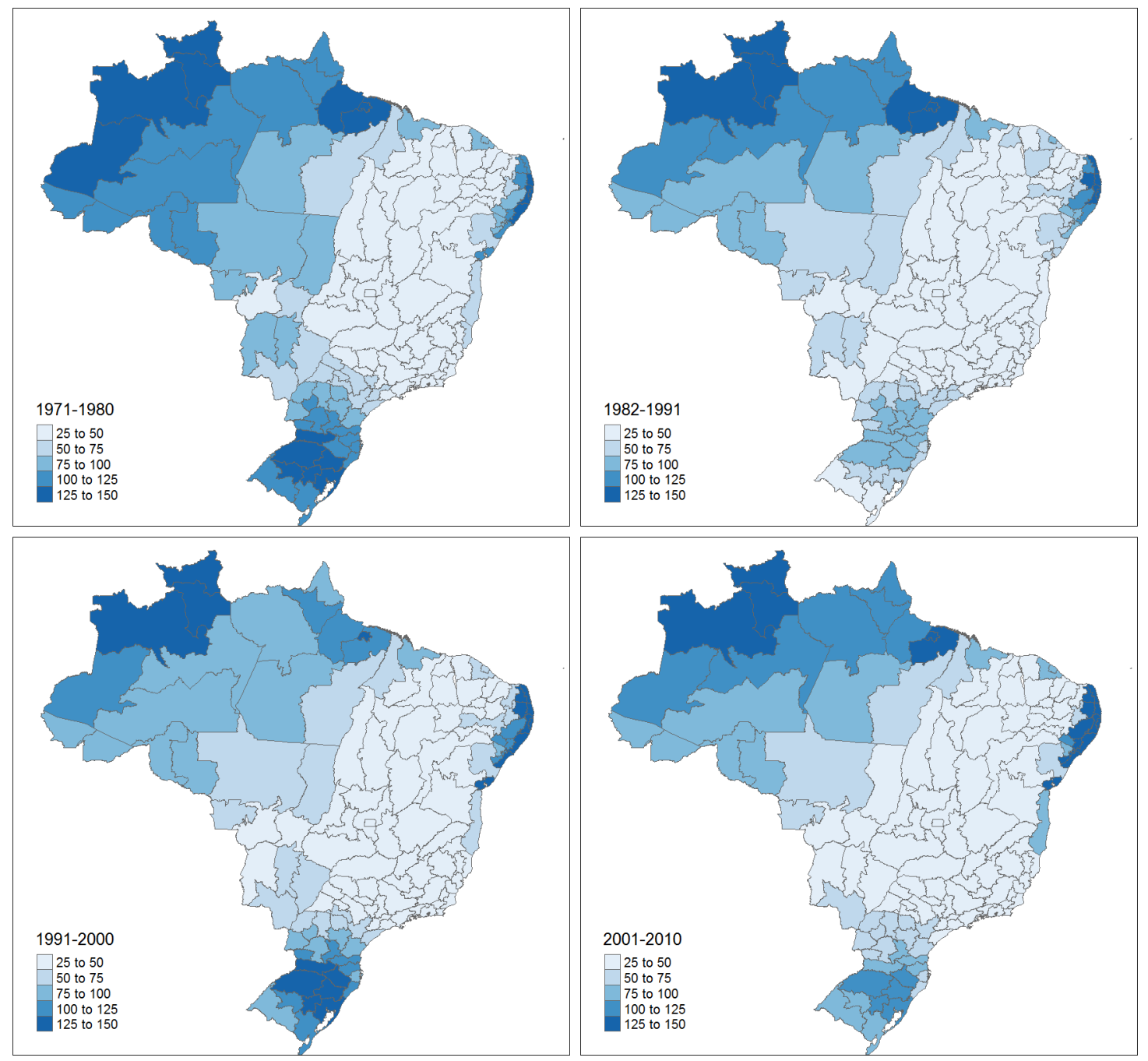

Appendix Figure 5: 10-year average rainfall in winter by census year, in $\mathrm{mm} / \mathrm{month}$

Notes: Daily rainfall is averaged out over the 10 years preceding the census. Data source: Brazilian Institute of Meteorology. 

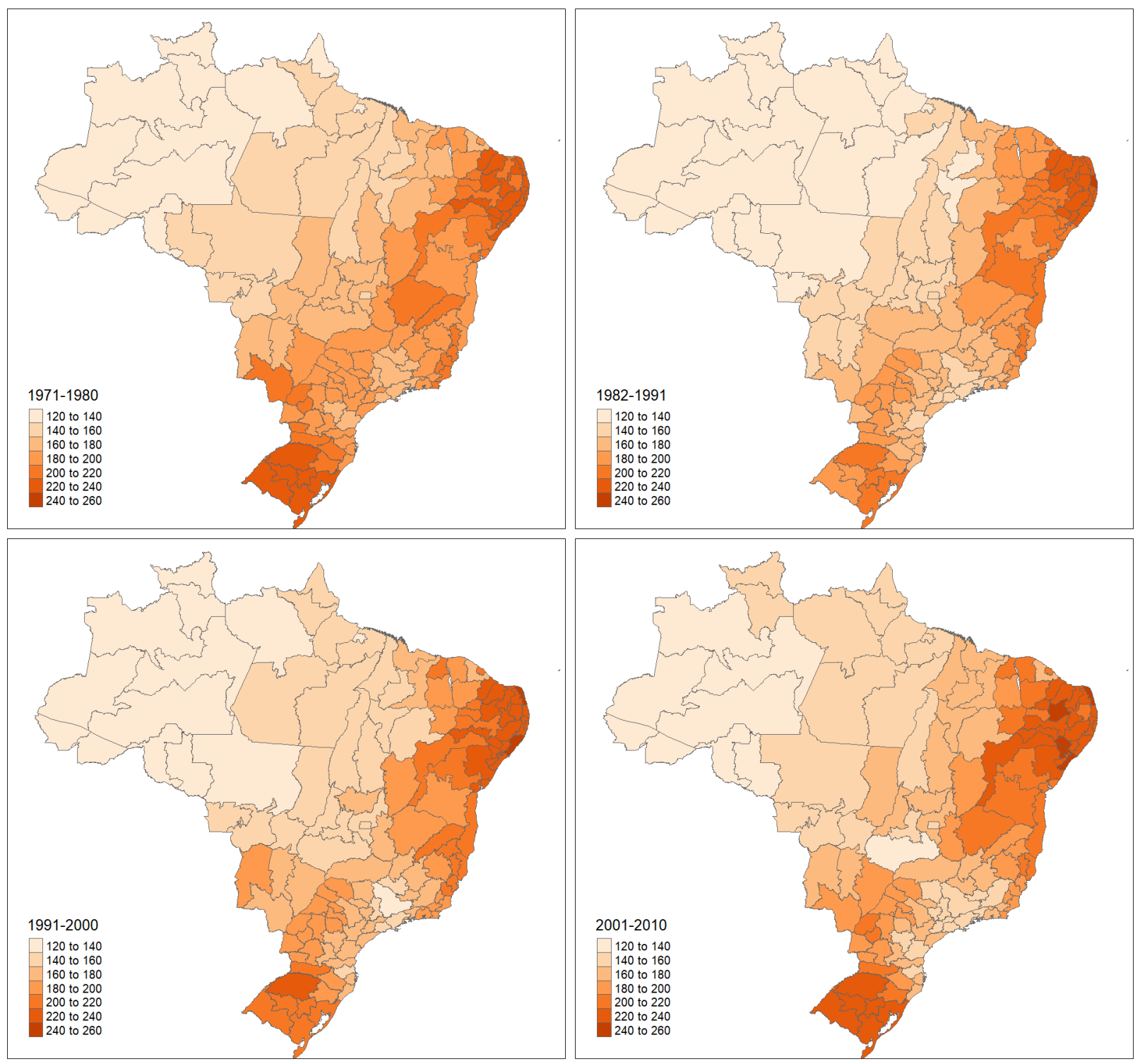

Appendix Figure 6: 10-year average sunshine in summer by census year, in hours/month

Notes: Daily sunshine hours are averaged out over the 10 years preceding the census. Data source: Brazilian Institute of Meteorology. 

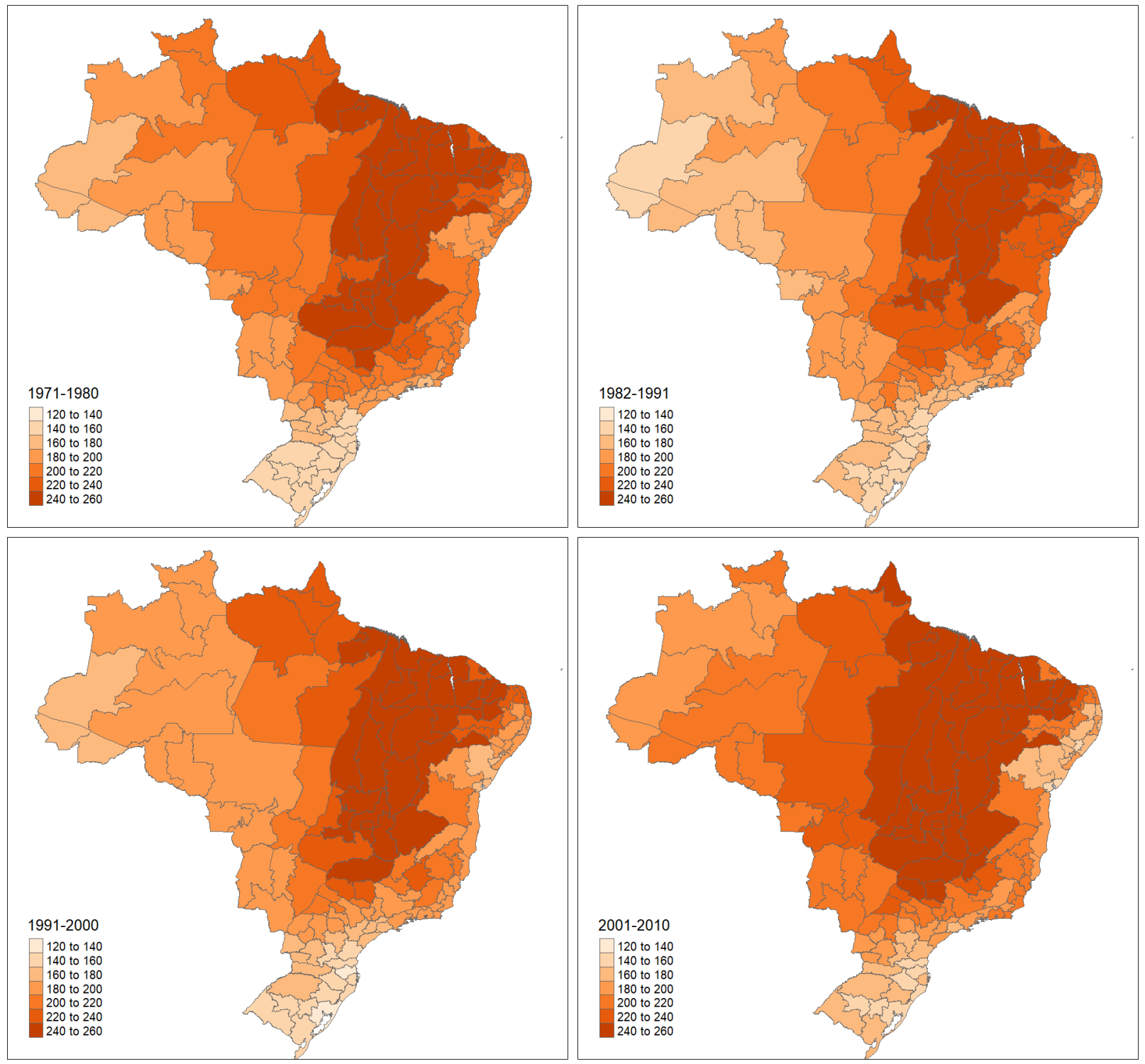

Appendix Figure 7: 10-year average sunshine in winter by census year, in hours/month

Notes: Daily sunshine hours are averaged out over the 10 years preceding the census. Data source: Brazilian Institute of Meteorology. 

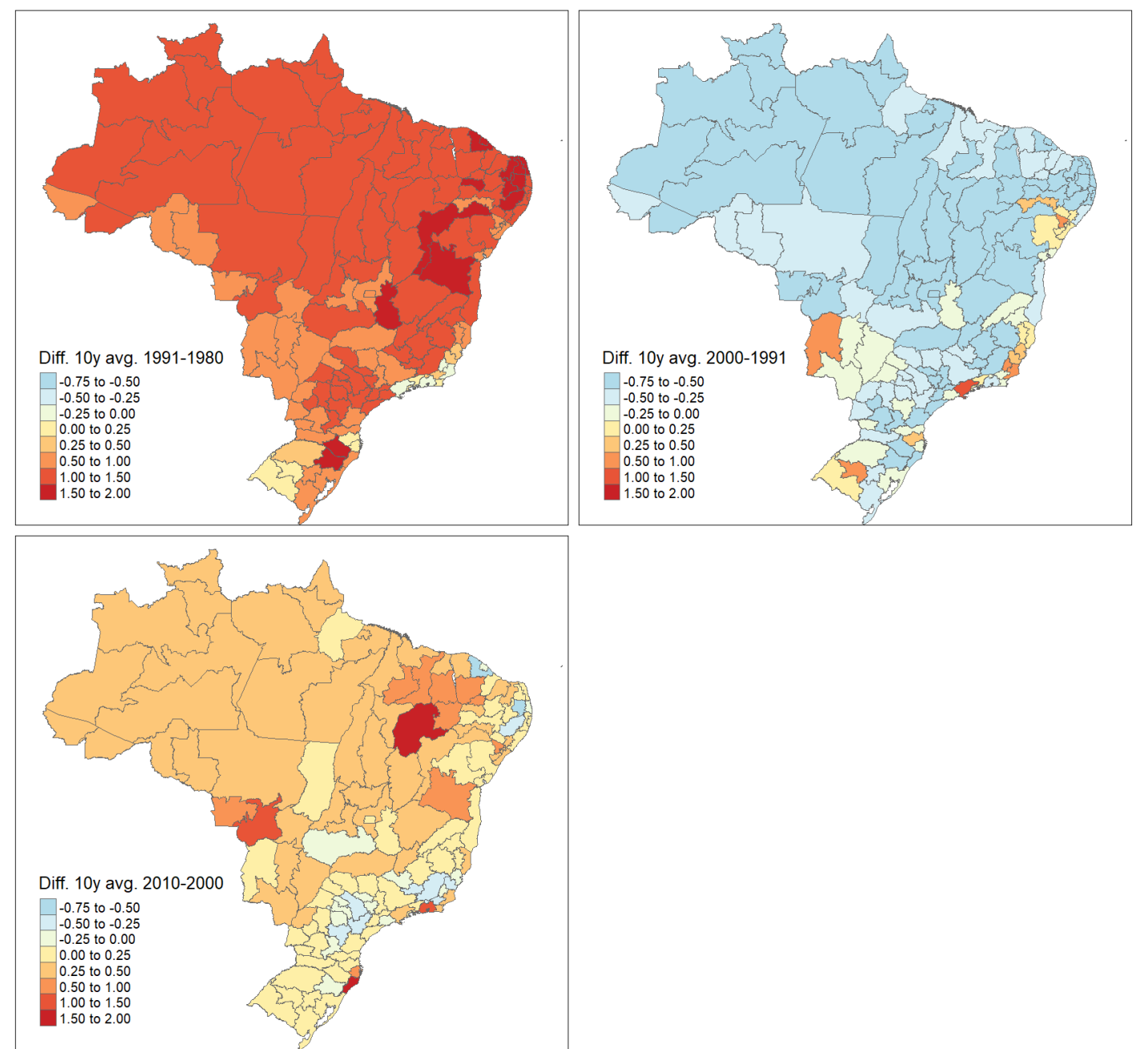

Appendix Figure 8: Change in summer temperature (10-year averages) by census year, in degrees Celsius

Notes: Difference in decadal average temperatures at census year. Data source: Brazilian Institute of Meteorology. 

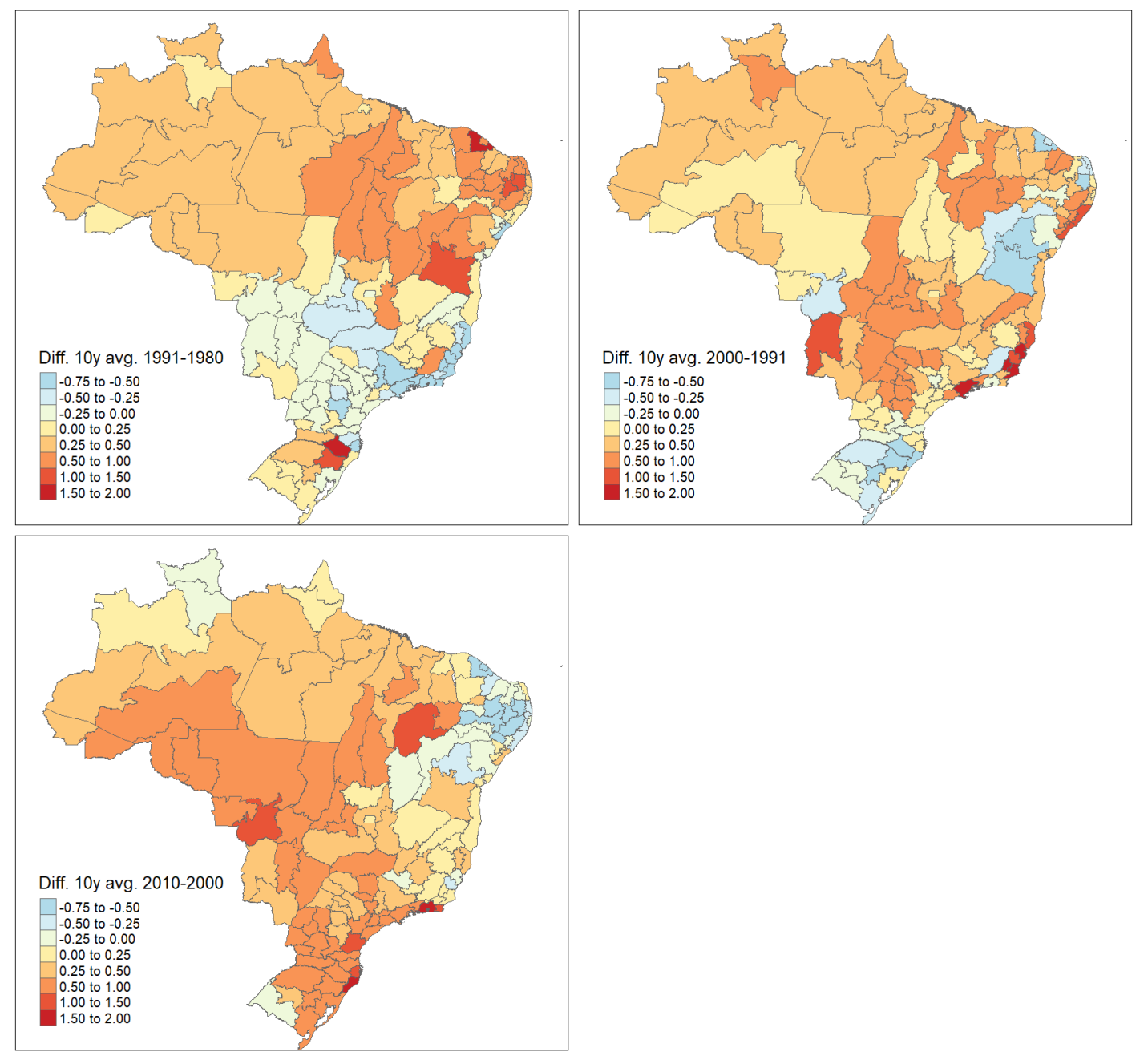

Appendix Figure 9: Change in winter temperature (10-year averages) by census year, in degrees Celsius.

Notes: Difference in decadal average temperatures at census year. Data source: Brazilian Institute of Meteorology. 

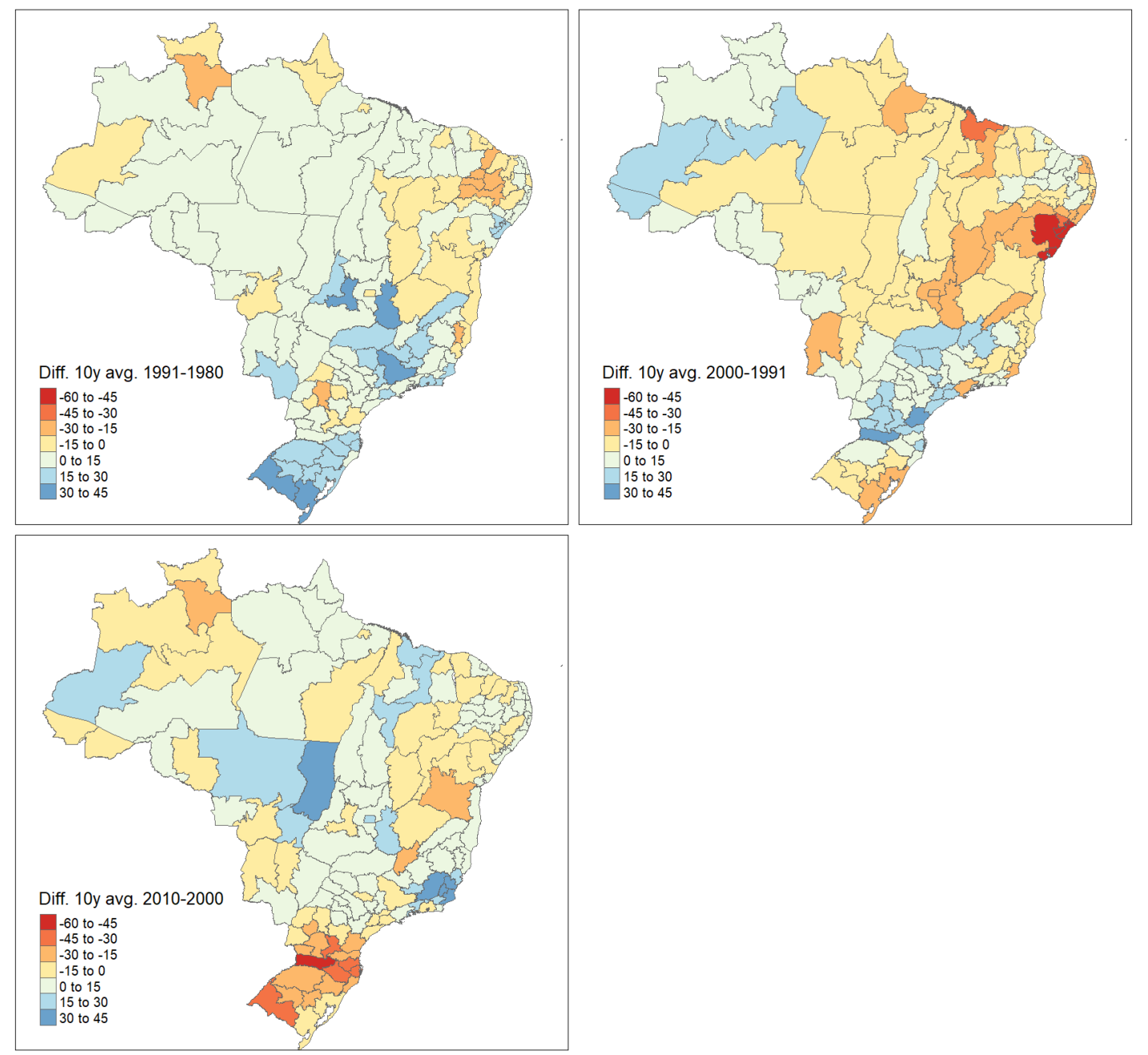

\section{Appendix Figure 10: Change in summer rainfall (10-year averages) by census year, in $\mathrm{mm} / \mathrm{month}$.}

Notes: Difference in decadal average rainfall at census year. Data source: Brazilian Institute of Meteorology. 

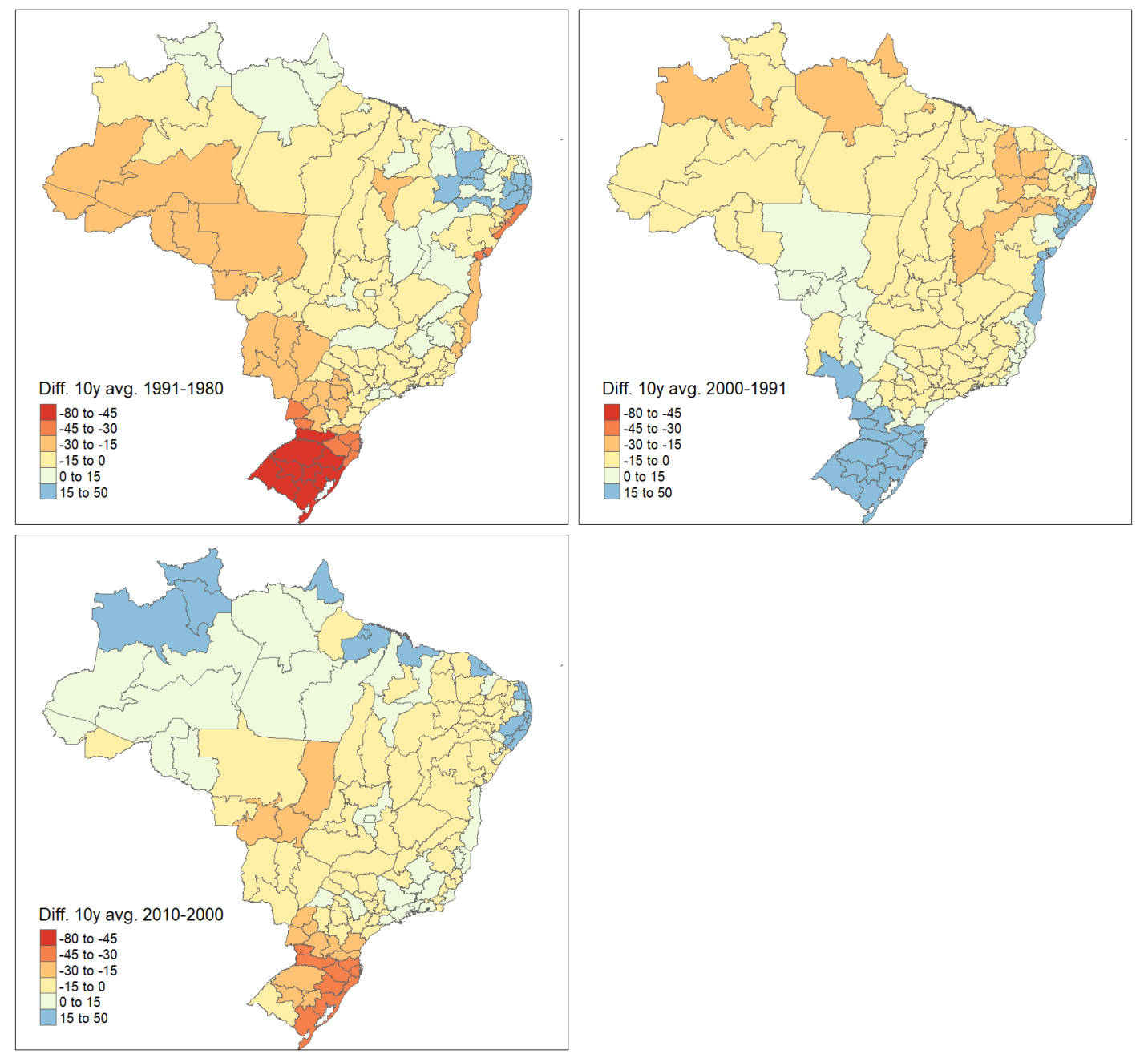

Appendix Figure 11: Change in winter rainfall (10-year averages) by census year, in $\mathrm{mm} / \mathrm{month}$.

Notes: Difference in decadal average rainfall at census year. Data source: Brazilian Institute of Meteorology. 

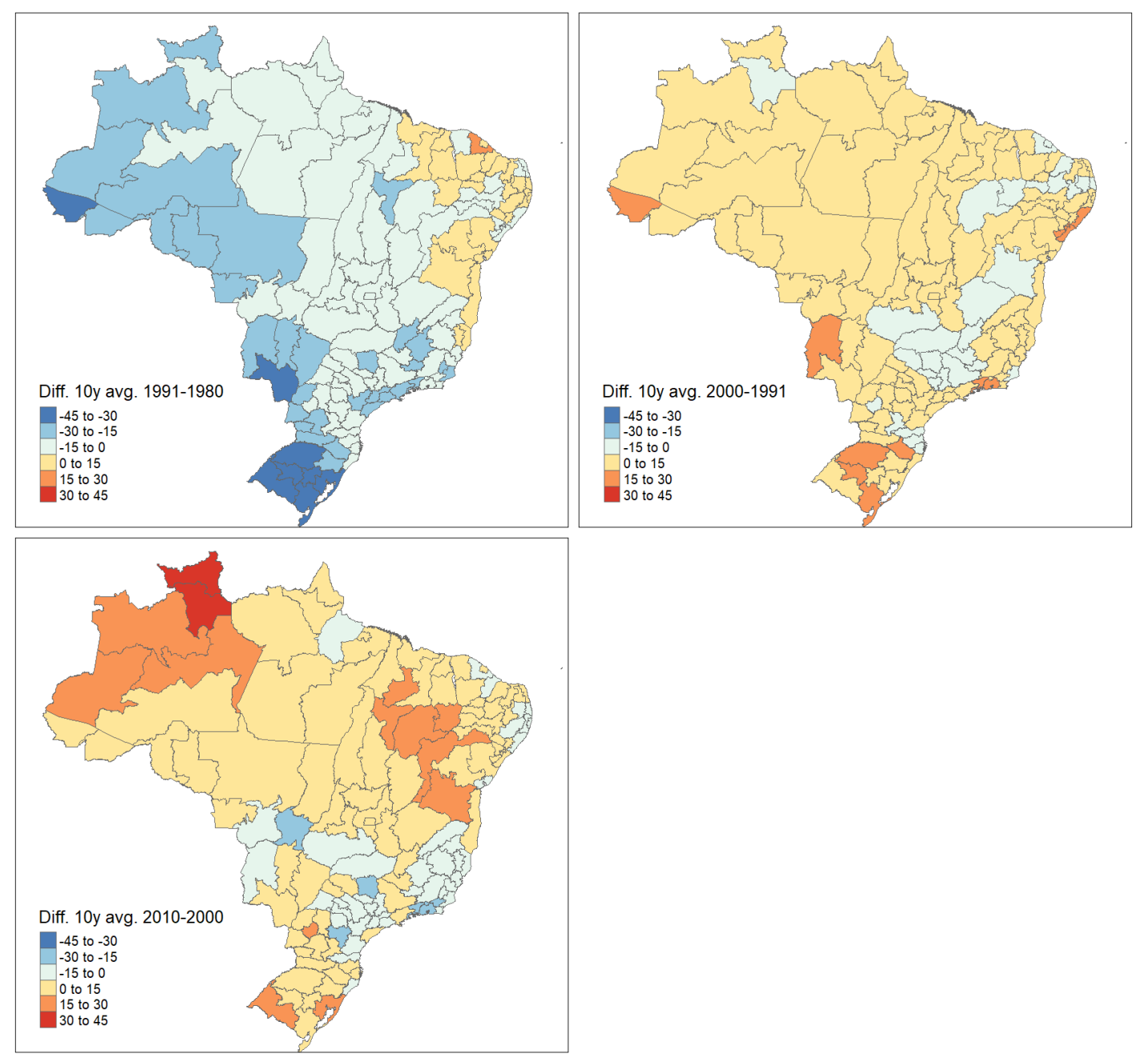

Appendix Figure 12: Change in summer sunshine (10-year averages) by census year, in hours/month.

Notes: Difference in decadal average sunshine hours at census year. Data source: Brazilian Institute of Meteorology. 

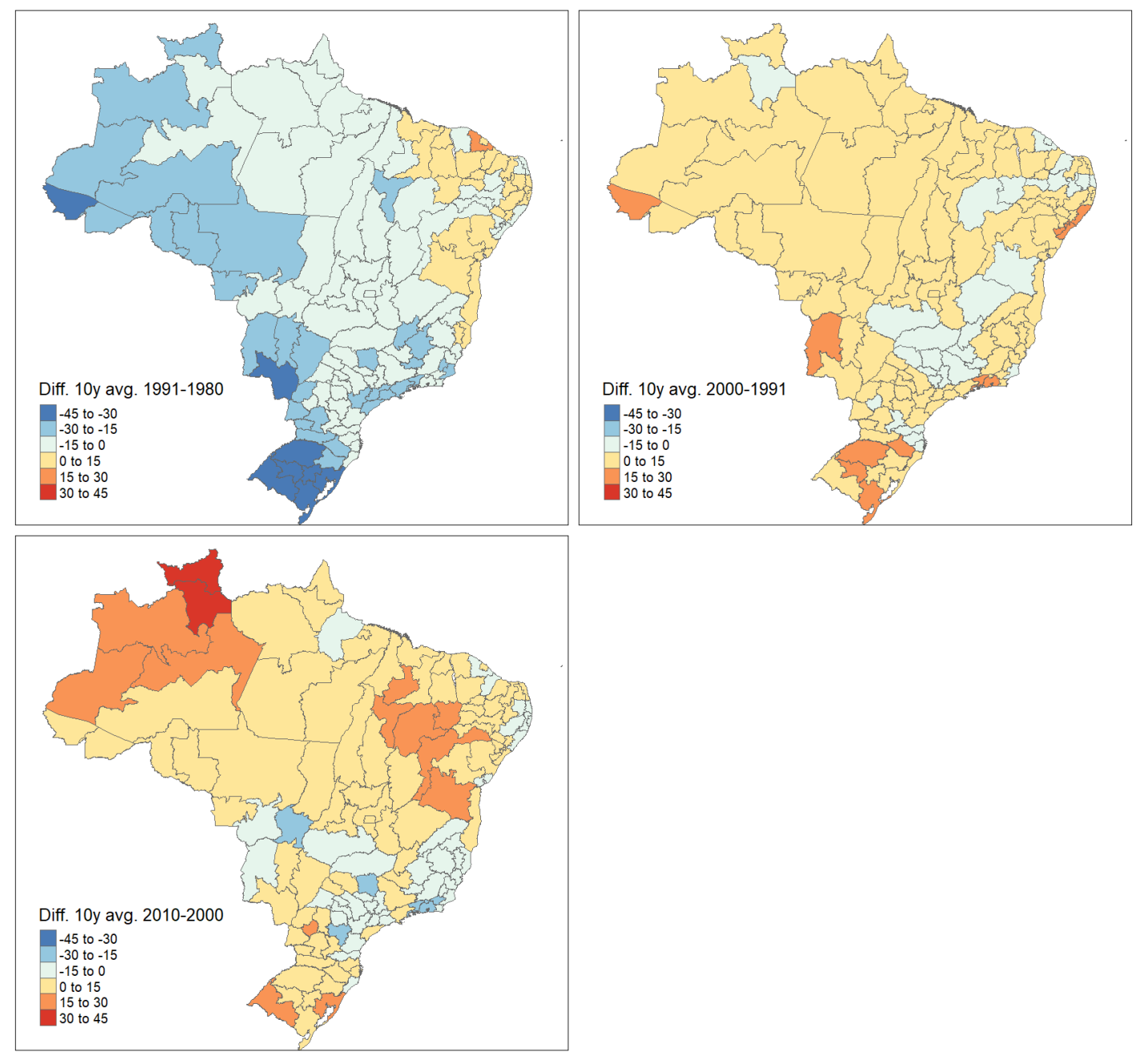

Appendix Figure 13: Change in winter sunshine (10-year averages) by census year, in hours/month.

Notes: Difference in decadal average sunshine hours at census year. Data source: Brazilian Institute of Meteorology. 

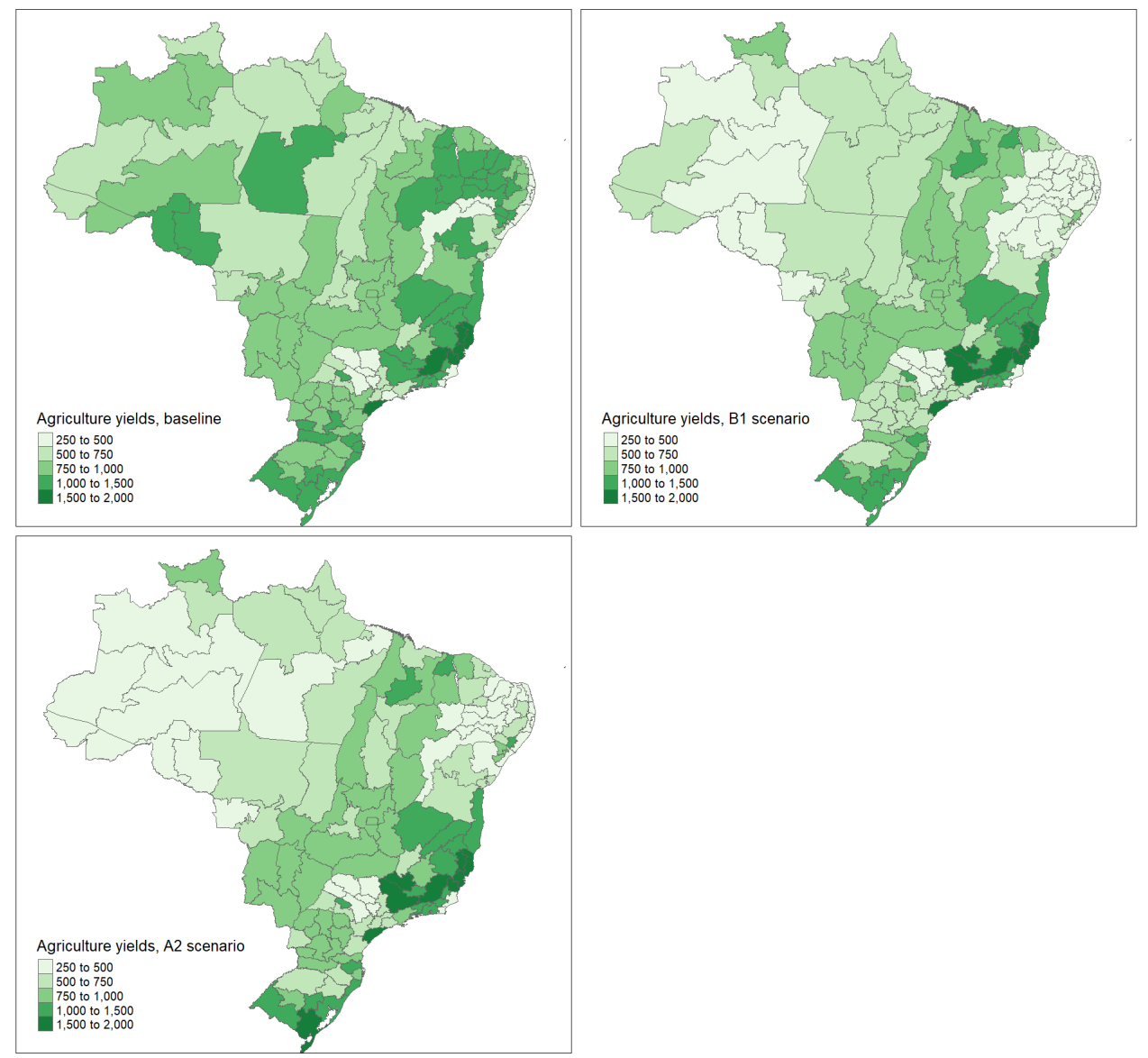

Appendix Figure 14: Agriculture yields (USD/ha), baseline and forecast periods (B1 and A2 scenarios)

Notes: Agriculture yields (in USD/ha) calculated as the weighted sum of potential crop yields obtained from the GAEZ dataset; weight is the share of the crop in total crop area over the 1990-2010 period. Baseline climate covers the 1961-1990 period; climate change forecast covers the 2041-2070 period. Data source: GAEZ. 


\section{Bartik shocks and labor market access}

(a) Bartik shocks

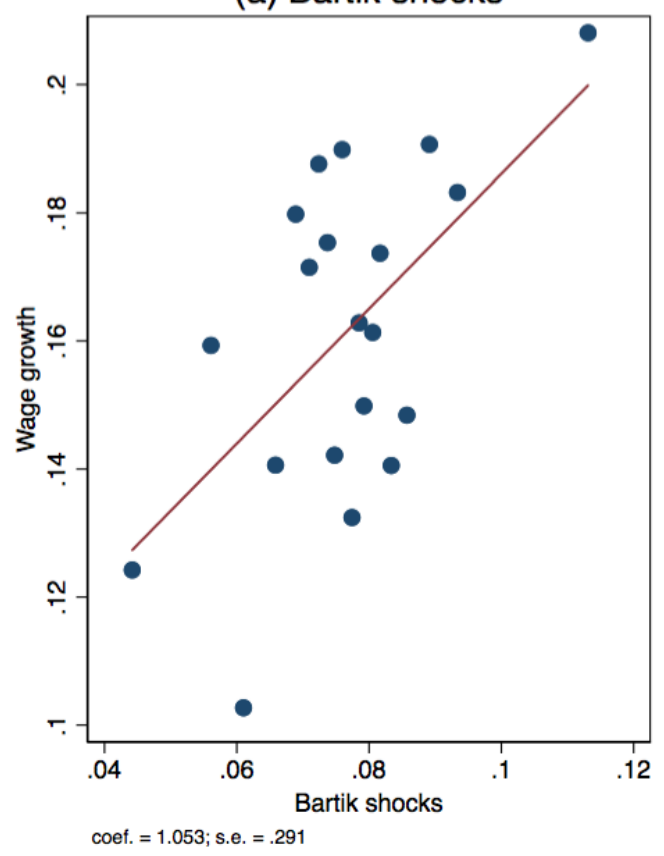

(b) Labor market access

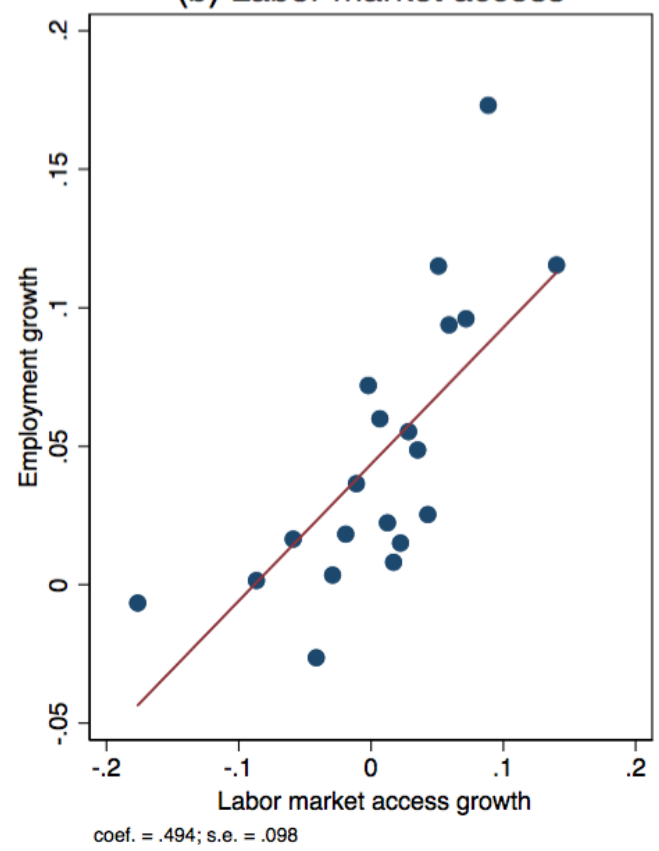

Appendix Figure 15: Correlation between instruments and endogenous variables

Notes: Figures present binned scatterplots and regression line. The observations are meso-region-sector pairs by year. Data source: Population Census, 1980-2010. 


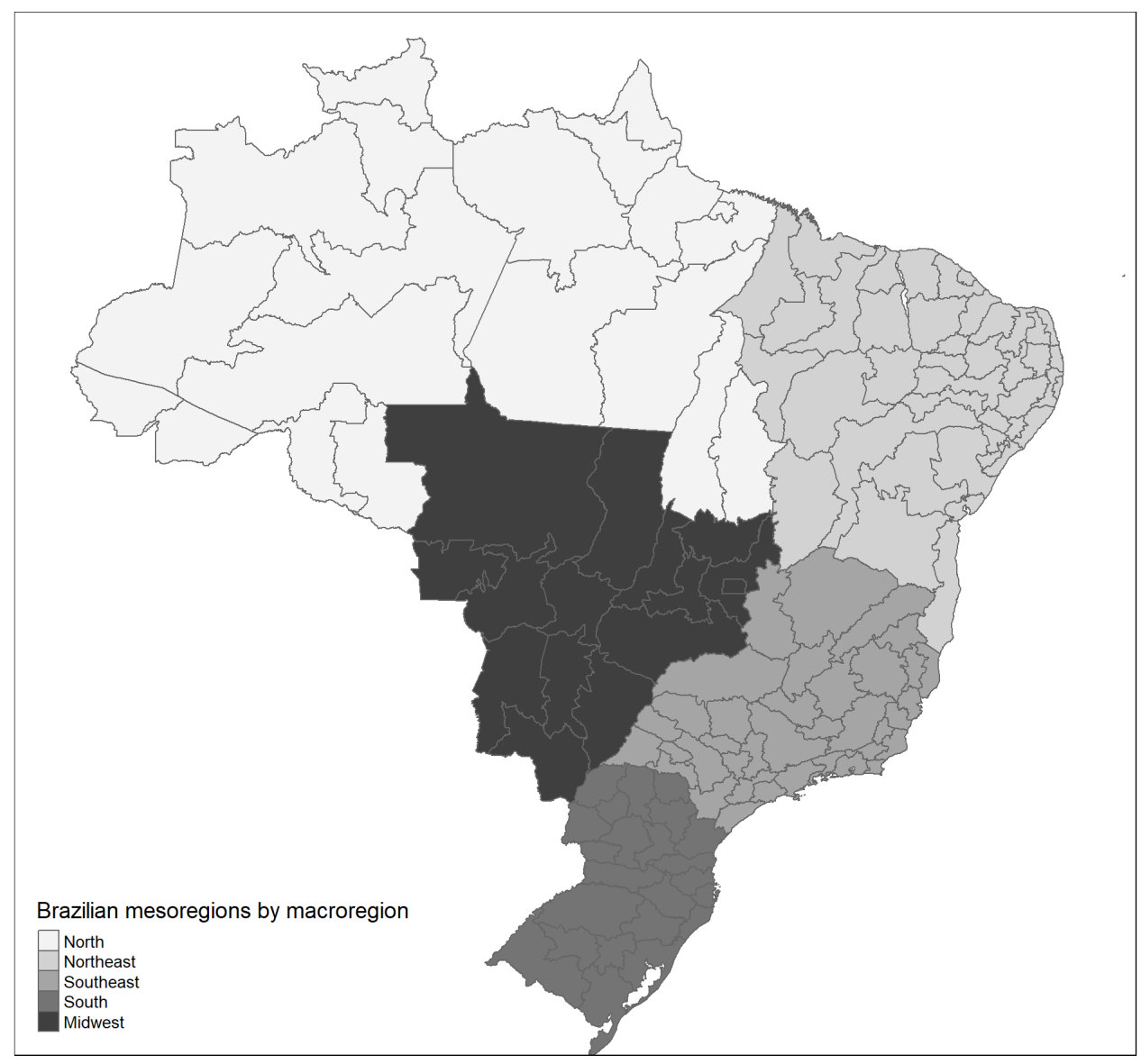

Appendix Figure 16: Brazil's macro-regions

Notes: The 135 meso-regions are grouped into five macro-regions. Data source: IBGE. 
Appendix Table 1: Summary statistics, by census year

\begin{tabular}{lcccc}
\hline & $(1)$ & $(2)$ & $(3)$ & $(4)$ \\
Mean/sd & 1980 & 1991 & 2000 & 2010 \\
\hline Agriculture share in labor force & 0.32 & 0.27 & 0.23 & 0.23 \\
& $(0.25)$ & $(0.21)$ & $(0.18)$ & $(0.15)$ \\
Out migration rates & 0.14 & 0.061 & 0.053 & 0.043 \\
& $(0.068)$ & $(0.025)$ & $(0.018)$ & $(0.017)$ \\
Non-agriculture wages (USD/hour) & 3.37 & 3.25 & 3.92 & 4.32 \\
& $(0.82)$ & $(0.98)$ & $(1.01)$ & $(0.89)$ \\
Agriculture wages (USD/hour) & 1.82 & 1.84 & 2.13 & 2.64 \\
& $(0.64)$ & $(1.00)$ & $(0.76)$ & $(0.77)$ \\
Rents (USD/room) & 30.9 & 29.5 & 38.1 & 33.7 \\
& $(15.5)$ & $(12.7)$ & $(19.0)$ & $(10.8)$ \\
\hline Number observations & 6596494 & 4357223 & 5562153 & 6802290 \\
Number meso-regions & 135 & 135 & 135 & 135 \\
\hline
\end{tabular}

Notes: Summary statistics calculated from Census microdata; sample consists of males and females aged 25 to 75 who made non-zero earnings in main occupation. Table shows meso-region averages weighted by population. Financial values in year 2010 USD. 1 USD = 1.838 BRL in 2010 (yearly average exchange rate). Data source: Population Census, 1980-2010. 


\section{Appendix Table 2: Structural coefficient estimates - alternative specification for climate amenities}

\begin{tabular}{|c|c|}
\hline & $\begin{array}{c}\text { Parameters } \\
(1) \\
\text { b/se }\end{array}$ \\
\hline \multicolumn{2}{|l|}{ Equation 1: housing supply } \\
\hline$\eta$ & $\begin{array}{c}0.75^{* * *} \\
(0.17)\end{array}$ \\
\hline \multicolumn{2}{|l|}{ Equation 2: indirect utility } \\
\hline$\sigma^{-1}$ & $\begin{array}{c}2.17^{* * *} \\
(0.75)\end{array}$ \\
\hline$\sigma^{-1} \lambda_{\text {summer temp }}$ & $\begin{array}{c}-18.8^{* * *} \\
(6.57)\end{array}$ \\
\hline$\sigma^{-1} \lambda_{\text {summer temp. }}{ }^{2}$ & $\begin{array}{c}0.72 * * * \\
(0.27)\end{array}$ \\
\hline$\sigma^{-1} \lambda_{\text {summer temp. }}{ }^{3}$ & $\begin{array}{l}-0.0093^{* *} \\
(0.0037)\end{array}$ \\
\hline$\sigma^{-1} \lambda_{\text {winter temp }}$ & $\begin{array}{c}3.19 * * * \\
(1.06)\end{array}$ \\
\hline$\sigma^{-1} \lambda_{\text {winter temp. }}{ }^{2}$ & $\begin{array}{l}-0.14^{* *} \\
(0.055)\end{array}$ \\
\hline$\sigma^{-1} \lambda_{\text {winter temp. }}{ }^{3}$ & $\begin{array}{l}0.0020^{* *} \\
(0.00094)\end{array}$ \\
\hline Equation 3: labor demand & \\
\hline$\beta^{m}$ & $\begin{array}{c}-0.19^{* * *} \\
(0.023)\end{array}$ \\
\hline$\beta^{a}$ & $\begin{array}{l}-0.050^{* *} \\
(0.020)\end{array}$ \\
\hline
\end{tabular}

Notes: $\quad$ Each of the $135 \times 2 \times 4=1,080$ is a meso region-sector-year. Parameter estimates from the system of two equations obtained from a 3SLS estimator which allows for an arbitrary error correlation. Endogenous employment and wages instrumented by Bartik shocks and inverse-cost weighted market access (interacted with sector of employment).Additional controls (sector fixed effects and state-year fixed effects in all equations; summer and winter rainfall and sunshine hours and s.d. of rainfall in indirect utility; climate variables in labor demand equation) inshided but not reported. Data source: Population Census, 1980-2010. 
Appendix Table 3: Simulated impact of climate change on aggregate migration rates. Alternative specification for climate amenities

\begin{tabular}{lcccc}
\hline & A2 scenario & \multicolumn{3}{c}{ B1 scenario } \\
& $(1)$ & $(2)$ & $(3)$ & $(4)$ \\
& GE & PE & GE & PE \\
\hline \multicolumn{4}{c}{ Experiment 1: climate impacts city } & amenity value \\
$\Delta$ Migration rate (\%) & 8.42 & 13.3 & 2.36 & 5.47 \\
$\Delta$ Agric. share (\%) & -0.090 & 0 & -0.060 & 0 \\
Experiment 2: climate & impacts agricultural productivity \\
$\Delta$ Migration rate (\%) & 0.84 & 1.51 & 0.77 & 1.67 \\
$\Delta$ Agric. share (\%) & -20.2 & -22.0 & -24.1 & -26.1 \\
Experiment 3: climate & impacts & amenities and ag. & productivity \\
$\Delta$ Migration rate (\%) & 10.2 & 15.7 & 4.61 & 8.37 \\
$\Delta$ Agric. share (\%) & -20.3 & -22.0 & -24.1 & -26.1 \\
\hline
\end{tabular}

Notes: Alternative specification: polynomial of degree three in summer and winter temperatures. Columns (1) and (3) show simulations from model with costly migration and general equilibrium effects; columns (2) and (4) show simulations from model with costly migration without general equilibrium effects. Climate change figures for 2041-2070 forecast. The effects represent changes relative to baseline climate, which is the long-term average over 1961-1990. Climate change scenarios: A2 (high emissions) and B1 (low emissions). Simulations use non-climate amenity levels of year 2010. Experiment 1: assumes that climate variables impact city amenity value only; experiment 2: climate variables impact agriculture productivity only; experiment 3: climate variables impact city amenity value and agriculture yields. Data source: CPTEC/INPE, GAEZ, and 1980-2010 Population Census. 


\section{A.2 Kriging Interpolation Technique}

We use a kriging interpolation technique to assign weather-station data to each of the 135 mesoregions. The kriging technique predicts the weather at a given point using a weighted average of the observed data in a neighborhood. It assumes that each geographic coordinate is a realization of a spatial process. The weights do not depend on the actual data points but on the variogram estimator, which describes the degree of spatial dependence of the stochastic process. The estimator uses a measure of the variance of the difference between two data points. The technique has an attractive feature: the predicted weather data equals the actual data. It performs well for weather/climate data, and is more flexible than usual techniques, such as nearest neighbor, or inverse distance weighting interpolation (Haas, 1990; Xavier et al., 2016). One downside of the interpolation technique is that it might cause spatial auto-correlation among the regression errors. This issue is mitigated by using clustered standard errors.

\section{A.3 Global and Regional Climate Models}

The INPE calculates regional climate change over South America by downscaling the Hadley Centre Global Environmental Model version 2 Earth System (HadGEM2-ES) and the Model for Interdisciplinary Research on Climate (MIROC5). The HadGEM2-ES is a physical climate model developed by Hadley Center; it includes many earth-system components and their interactions, such as terrestrial, ocean and gas-phase tropospheric chemistry (Chou et al., 2014b,a; Collins et al., 2011). The MIROC5, developed by a collaboration between Japanese research centers, also includes atmosphere and ocean circulation models (Chou et al., 2014b,a; Watanabe et al., 2010). The downscaled models are called "Regional Climate Models (RMCs)" and are more accurate than GCMs: while RCMs use grid sizes of 20km, GCMs adopt grid sizes of 200 to $400 \mathrm{~km}$.

\section{A.4 The GAEZ Project}

To understand the relationship between climate and agriculture productivity, we use the GAEZ grid-level data set. The GAEZ data draw on state-of-the-art agronomic models combined with high-resolution data on land characteristics and climatic conditions. The methodology was developed by the International Institute for Applied System Analysis (IIASA) and the Food and Agriculture Organization of the United Nations (FAO). One of the main outputs of the model is the crop potential yields - the upper limits for the crops production. The model that generates daily potential crop yield data is based on a crop growth cycle from emergence to maturity that predicts the attainable crop production given a variety of climatic and soil conditions, as well as use of inputs such as water resources and labor intensity, and farm management. To predict crop growth the model also makes use of detailed agronomic knowledge over crop parameters, such as harvest index, maximum leaf area, and maximum rate of photosynthesis.

According to Fischer et al. (2012), the model is estimated following five steps, or modules. First, climate variables and indicators are calculated for each grid-cell. Temporal interpolations can be used to transform monthly to daily data, which is required for thermal and soil moisture regimes to calculate potential and actual evapotranspiration of plants considering the crop cycle length. ${ }^{47}$ Based on these indicators, a multiple-cropping zones classification is produced for rainfed and irrigated conditions.

\footnotetext{
${ }^{47}$ Many climatic variables are also used as inputs. Thermal regime is captured by the annual temperature (mean and range), temperature during growing period, frost-free period, thermal zones (accumulated temperature sums for average daily temps). Moisture conditions are approximated by annual rainfall (mean,
} 
Second, they calculate maximum attainable biomass and yield from radiation and temperature regimes. The growth of each crop type is tested for several time periods with separate analysis for irrigated and rain-fed conditions, which impact crop evapotranspiration and crop water deficit during the growing cycle. The growing dates and cycle length (days from sowing to harvest) producing the maximum yield define the optimum crop calendar of each crop type in each gridcell (when the grid conditions permit the crop's cultivation). ${ }^{48}$ The types also differ with assumed inputs level. Low input level crops are considered to have low harvest index, a measure of yield efficiency, and inferior leaf area index as a result of management limitations. In contrast, high input level crops, with advanced field management, present optimum plant densities with high leaf area index.

Third, after calculating all parameters for a large number of crop sub-types, they compute yield reduction factors, also named agro-climatic constraints, to adjust for average climatic conditions (due to year-to-year variability of soil moisture supply), pests, diseases and weed constraints, water stress, excessive wetness, and frosts. The reduction factors are calculated for each crop and by level of inputs, and are applied to the results from the second step. ${ }^{49}$

Fourth, they calculate yield reduction factors based on agro-edaphic constraints, or limitations by soil and terrain conditions. Soil conditions refer to nutrient availability and retention capacity, oxygen, salinity, sodicity, and toxicities conditions, as well as soil management constraints by crop and by specific input usage. Terrain conditions mainly refer to slope and altitude classes. The yield reduction factors are calculated by crop types, input level, soil types and slope classes, and applied to the results from the second step for each grid cell.

The fifth and final step is the integration of all previous steps. It considers the agro-climatic evaluation for biomass and yield calculated in the second and third step and uses the soil information from the forth step to adjust the yields by soil and slopes for each grid-cell, always separately for rain-fed and irrigated conditions. Data on land cover pattern (e.g. water bodies), protected areas and restrictions for agricultural use are also employed in the calculations.

Data are available for 11 crop groups, 49 crops, 92 crop types, and 280 crop subtypes. The unit of measurement of potential yields is tonnes per hectare. All data are calculated for a 5 arc-minute and 30 arc-second resolution (approximately 10-km grid) under contemporary climate conditions (30-year average from 1961 to 1990), and under IPCC climate change scenarios (B1, B2, A1FI, and A2) over future periods (2011-2040, 2041-2070, and 2071-2100). The GCMs available are the HadCM3 (UK), ECHAM4 (Germany), CSIRO (Australia), and CGCM2 (Canada).

The GAEZ estimates can be accessed by choosing the region (countries, continents, regions), time span of interest (historical or forecast), water supply systems (rain-fed or irrigated production), input and management levels (low-level, intermediate-level, and high-level), and temperature and moisture constraints. ${ }^{50}$ The output is the crop potential yield by grid in the selected area.

coefficient of variation, standard deviation), fournier index (mean, coefficient of variation, standard deviation), evapotranspiration (sum of evaporation and plant transpiration to atmosphere), seasonal and quarterly aridity index Wind speed, sunshine hours, and relative humidity are also included in the model, as well as the length of growing period by crop.

${ }^{48}$ The length of growth cycle (in days) and the harvested part of the plant (grain, seed, leaves, among others) for each 280 crop types are in Table A-4-4 in Fischer et al. (2012). Crop types characterize various sub-types within a plant species, including differences in crop cycle length, growth and development parameters. For example, soybean has six different types, which differ by climate (tropical/subtropical, and temperate/subtropical) and by length (105, 120, and 135 days).

${ }^{49}$ According to Fischer et al. (2012), some of the constraint ratings were obtained through expert opinion.

${ }^{50}$ Assuming low-level inputs means that farm production is for subsistence using traditional labor techniques and no application of chemicals and nutrients; assuming intermediate-level inputs means that farm 


\section{A.5 Model Appendix}

This section contains the derivation of the expected utility. The utility of individual $n$ from city $j$ living in city $k$ and working in sector $s$ is $V_{n j k s}=V_{k s}+\mu_{j k s}+\epsilon_{n k s}$. Assuming $\epsilon_{n k s}$ is i.i.d and follows an extreme value distribution of type $\mathrm{I}$, that is, $F(\epsilon)=e^{-e^{-\epsilon}}$, the probability of migrating from $j$ to $k$ and working in sector $s$ is:

$$
\begin{aligned}
& P(\text { choose } k \text { and } s \mid \text { start in } j)=P\left(V_{k s}+\mu_{j k}+\epsilon_{k s}>V_{l m}+\mu_{j l}+\epsilon_{l m}, \forall l \neq k, \forall m \neq s\right) \\
& =\int_{-\infty}^{\infty} P\left(V_{l m}+\mu_{j l}+\epsilon_{l m}<v, \forall l \neq k, \forall m \neq s\right) P\left(V_{k s}+\mu_{j k}+\epsilon_{k s}=v\right) d v \\
& =\int_{-\infty}^{\infty} \Pi_{l \neq k} \Pi_{m \neq s} e^{-e^{-\left(v-\left(V_{l m}+\mu_{j l}\right)\right)}} e^{-\left(v-\left(V_{k s}+\mu_{j k}\right)\right)} e^{-e^{-\left(v-\left(V_{k s}+\mu_{j k}\right)\right)}} d v \\
& =\int_{-\infty}^{\infty} e^{-\left(v-\left(V_{k s}+\mu_{j k}\right)\right)} \Pi_{l} \Pi_{m} e^{-e^{-\left(v-\left(V_{l m}+\mu_{j l}\right)\right)}} d v \\
& =\int_{-\infty}^{\infty} e^{-v} e^{\left(V_{k s}+\mu_{j k}\right)} \Pi_{l} \Pi_{m} e^{-e^{-\left(v-\left(V_{l m}+\mu_{j l}\right)\right)}} d v \\
& =e^{\left(V_{k s}+\mu_{j k}\right)} \int_{-\infty}^{\infty} e^{-v} e^{-\sum_{l} \sum_{m} e^{-\left(v-\left(V_{l m}+\mu_{j l}\right)\right)}} d v \\
& =e^{\left(V_{k s}+\mu_{j k}\right)} \int_{-\infty}^{\infty} e^{-v} e^{-e^{-v} \sum_{l} \sum_{m} e^{\left(V_{l m}+\mu_{j l}\right)}} d v
\end{aligned}
$$

Define $\beta=\sum_{l} \sum_{m} e^{\left(V_{l m}+\mu_{j l}\right)}$ and $t=-e^{-v \beta}$. Then,

$$
\begin{aligned}
P(\text { choose } k \text { and } s \mid \operatorname{start} \text { in } j) & =e^{\left(V_{k s}+\mu_{j k}\right)} \int_{-\infty}^{0} \frac{1}{\sum_{l} \sum_{m} e^{\left(V_{l m}+\mu_{j l}\right)}} e^{t} d t \\
& =\frac{e^{\left(V_{k s}+\mu_{j k}\right)}}{\sum_{l} \sum_{m} e^{\left(V_{l m}+\mu_{j l}\right)}} \int_{-\infty}^{0} e^{t} d t \\
& =\frac{e^{\left(V_{k s}+\mu_{j k}\right)}}{\sum_{l} \sum_{m} e^{\left(V_{l m}+\mu_{j l}\right)}} .
\end{aligned}
$$

To calculate changes in welfare we need the expected utilities conditional on city choice, that is, $E\left(V_{i j k s} \mid\right.$ choose $k$ and $\left.s\right)=E\left(\max _{l, m} V_{i j l m}\right)$. The CDF of the maximum of an EV random variable is

$$
\begin{aligned}
F\left(\max _{l, m} V_{j l m} \leq v\right) & =P\left(V_{1 a}+\mu_{j 1}+\epsilon_{1 a} \leq v\right) P\left(V_{1 m}+\mu_{j 1}+\epsilon_{1 m} \leq v\right) \ldots P\left(V_{J m}+\mu_{j J}+\epsilon_{J m} \leq v\right) \\
& =\Pi_{l} \Pi_{m} F\left(v-V_{l m}-\mu_{j l}\right) \\
& =\Pi_{l} \Pi_{m} e^{-e^{-v+\left(V_{l m}+\mu_{j l}\right)}} \\
& =e^{-\sum_{l} \sum_{m} e^{-v+\left(V_{l m}+\mu_{j l}\right)}} \\
& =e^{-e^{-v} \sum_{l} \sum_{m} e^{\left(V_{l m}+\mu_{j l}\right)}} \\
& =e^{-\beta e^{-v}}
\end{aligned}
$$

production is consider as market oriented, but manual work is used as well as a low-level of mechanization; and assuming high-level inputs means that production is fully mechanized, low-labor intensive and applies chemical and nutrients optimally in the field. 
where $\beta=\sum_{l} \sum_{m} e^{\left(V_{l m}+\mu_{j l}\right)}$.

The expected value of the max is:

$$
\begin{aligned}
E\left(\max _{l, m} V_{j l m}\right) & =\int_{-\infty}^{\infty} v \beta e^{-\left(v+\beta e^{-v}\right)} d v \\
& =\int_{-\infty}^{\infty} v \beta e^{-v} e^{-\beta e^{-v}} d v \\
\text { let } t & =\beta e^{-v} \\
& =-\int_{0}^{\infty}-(\ln \beta-\log t) e^{-t} d t \\
& =-\left[\int_{0}^{\infty} \ln t \exp ^{-t} d t-\int_{0}^{\infty} \log \beta e^{-t} d t\right] \\
& =\gamma+\int_{0}^{\infty} \log \beta e^{-t} d t \\
& =\gamma+\log \beta \\
& =\gamma+\log \sum_{l} \sum_{m} e^{\left(V_{l m}+\mu_{j l}\right)},
\end{aligned}
$$

where $\gamma \approx 0.577$ is the Euler-Mascheroni constant. 